\title{
DEBATES CONTEMPORÁNEOS SOBRE LA PLANIFICACIÓN TERRITORIAL Y LA GESTIÓN URBANA
}

\author{
JORGE ANDRÉS RIVERA PABÓN ${ }^{1}$
}

Recibido el 8 de octubre de 2012 y aprobado el 2 de abril de 2013

\section{RESUMEN}

En la actualidad, la planificación territorial es objeto de intensos debates y ejercicios revisionistas dados los cuestionamientos que ha recibido en términos de sus alcances, finalidad y sentido de aplicación en un contexto de liberalización de la economía y de políticas de desregulación enfocadas al desarrollo de la libertad de inversión en todos los planos de la vida social y del uso del espacio geográfico. Por esta razón, el presente artículo plantea un panorama general de las discusiones surgidas en torno a este ámbito técnico-político, y a partir del análisis crítico e indagación de sus postulados y principios propone nuevas posibilidades de reflexión y actuación. De igual forma, se exponen con base en algunos ejemplos o casos de estudio en Colombia, América Latina y Cataluña (España), los conflictos (sociales, ambientales-territoriales) acaecidos en el marco del escenario contemporáneo neoliberal y las diversas respuestas desde la gestión institucional, la acción de los movimientos sociales y la organización comunitaria.

\section{PALABRAS CLAVE}

Planificación territorial, gestión urbana-local, conflicto (social, ambiental-espacial), participación ciudadana, neoliberalismo.

\section{CONTEMPORARY DEBATES ABOUT TERRITORIAL PLANNING AND LOCAL MANAGEMENT}

\begin{abstract}
Nowadays, territorial planning is a subject of intense debates and revisionist exercises given the questioning existing about its scope, objectives and application purposes in the context of economic liberalization and deregulation policies aimed at developing freedom of investment at all levels of social life and the use of geographical space. For this reason, this article presents an overview of the discussions emerged around this technical-political field, and from critical analysis and inquiry of its postulates and principles, proposes new reflection and acting possibilities. Similarly, based on some examples or study cases in Colombia, Latin America and Catalonia-Spain, the article describes conflicts (social, environmental and territorial) occurring in the context of the contemporary neoliberal scenario and several responses from institutional management, town and regional planning, the social movements, and community organization actions.
\end{abstract}




\section{KEY WORDS}

Territorial planning; urban local management; spatial, social and environmental conflict; citizen participation; neoliberalism.

\section{INTRODUCCIÓN}

A través del presente documento se plantean algunas reflexiones derivadas de los debates más recientes sobre la planificación territorial y la gestión urbana. Para ello, se consideran como referencia las posiciones manifestadas por reconocidos especialistas en artículos y trabajos escritos, o durante su participación en diversos eventos académicos y técnicos ${ }^{2}$ que han tenido por objeto el análisis de este tipo de temáticas.

En efecto, se advierte cómo estos autores a partir de ideas coincidentes, complementarias, o desde perspectivas opuestas, expresan con gran prolijidad las discusiones de mayor actualidad y vigencia en torno al quehacer de una actividad tan compleja como es la definición de políticas públicas, el diseño y posterior ejecución de planes territoriales que inciden en la vida cotidiana de un gran número de personas y colectividades sociales.

Por lo tanto, el propósito del artículo es formular con base en los temas discutidos, una serie de proposiciones y fundamentos de estas labores de la administración pública y la función estatal, justamente en un contexto económico y político de hegemonía neoliberal que ha producido nuevos escenarios de controversia en los equipos de planificadores y tomadores de decisiones, los cuales gravitan entre la generación de propuestas de ruptura al modelo o su reproducción.

\section{IDEAS EN DISCUSIÓN}

Los planteamientos que se exponen a continuación son fruto del ejercicio académico de interpretación dialéctica y examen crítico de los objetivos, principios tutelares y formas de actuación de la planificación territorial y la gestión urbana, entendidos estos como instrumentos sine qua non para la consecución de fines de tan elevada importancia, como son el mejoramiento continuo de los servicios e infraestructuras de seguridad social, provisión de vivienda, equipamientos colectivos, formación ciudadana, protección ambiental, entre otros aspectos que deben redundar en la superación de la pobreza, la equidad y el fomento del desarrollo comunitario.

La participación de los equipos técnicos en la planificación territorial y el planeamiento entendido como una decisión política 
Indudablemente la planificación es un proceso cíclico que tiene como etapa determinante la toma de decisiones orientada a alcanzar los objetivos de bienestar, justicia social, sustentabilidad ambiental, productividad, etc. Para tal empresa, se hace necesario el trabajo y argumentos de los técnicos expertos, los cuales a partir de un análisis territorial, en el mejor de los casos, interdisciplinario, multiescalar y multicriterio, deberían definir y proponer directrices y líneas de actuación a los entes de gobierno para decidir sobre el futuro del territorio.

Al mismo tiempo, es preciso señalar que las decisiones tomadas no son neutrales, son el resultado de un proceso de "consenso" no desprovisto de tensión y disputa entre posturas antagónicas, reflejo de los múltiples intereses que tienen los agentes y actores sociales que coexisten en el espacio geográfico ${ }^{3}$. En este sentido, un buen ejemplo de las dificultades y limitantes que enfrenta la praxis de la planificación territorial es el exhibido por el arquitecto, urbanista y académico español Fernando de Terán (citado en Serra, 2009, 16) en un artículo escrito en el diario El País de España a propósito de la celebración del año Cerdà ${ }^{4}$, en el cual subraya que "el problema fundamental es de naturaleza política, pues como se ha percibido en España, en lo últimos años se ha consumido mucho suelo, mucho territorio y mucho litoral", proceso efectuado dentro de lo legalmente posible, además con un fuerte respaldo político y social, muy a pesar de los estudios y puntos de vista racionales y razonados de los técnicos que evidencian los impactos profundos de esta realidad territorial ${ }^{5}$.

En esta misma dirección interpretativa se ubica la postura del experto en análisis urbanos y territoriales de la Universidad IUAV de Venecia, el urbanista italiano Francesco Indovina $(2004$, p. 1) al afirmar que "el plan no es tanto de los técnicos como de la administración, y es ésta la que debe asumir las responsabilidades" ante los escenarios donde se presenta la posibilidad de "negociar" su función de protectora del interés general sobre los deseos, beneficios o réditos particulares pretendidos por los promotores inmobiliarios, las empresas constructoras, las compañías de bienes raíces, y el juego de la especulación y rentabilidad del uso del territorio.

De este modo, por las razones expuestas con antelación es improcedente e inaceptable responsabilizar unilateralmente a los técnicos de los problemas urbanos ${ }^{6}$ y las decisiones políticas frente a estos, o también de los impactos desastrosos relacionados con los conflictos socio-naturales que han ocurrido con mayor frecuencia en los últimos años (inundaciones, avalanchas, deslizamientos y otros movimiento en masa, etc.) $)^{\text {. }}$.

En particular, para el caso colombiano (y extensivo para América Latina) habría que señalar que los problemas urbanos responden a la lógica histórica de construcción social del territorio, marcada por aspectos como las migraciones de población campesina a la ciudad debido a la desestructuración de los "proyectos de vida digna" en extensas áreas rurales, con efectos negativos urbanos como son la innegable segregación 
residencial e informalidad de los espacios de hábitat popular, producto de la enorme desigualdad e injusticia social que caracteriza a las sociedades inscritas en el marco del capitalismo dependiente.

Justificadamente, como lo revela uno de los principales investigadores y conocedores de la problemática urbana de Colombia, el urbanista francés Jacques Aprile-Gniset (2007, p. 2), profesor de la Universidad del Valle, la especificidad de la ciudad colombiana contemporánea encuentra un nivel de explicación en los conflictos y problemas agrarios:

La problemática urbana se articula
inevitablemente con algo tan viejo como es la
instauración y el desenvolvimiento de la
propiedad privada; asimismo con la división
social y espacial del trabajo, y con las
contradicciones nacidas de la inevitable
separación/dominación que opera en los
ámbitos del binomio campo-ciudad.
Recorriendo ciudades nacientes o viejas que se
han ido llenando de casuchas pobladas con
refugiados, y campos baldíos o deshabitados,
este vaivén pendular me ha llevado a intuir la
estrecha unidad dialéctica de ambos
fenómenos socio-territoriales: "La violencia
agraria es la partera de la ciudad".

Con base en la reflexión precedente Aprile-Gniset (2007, p. 25) concluye que "muchas ciudades colombianas tuvieron un parto conflictivo o sangriento, naciendo de traumas y convulsiones en las cuales se suman las tensiones urbanas con los conflictos territoriales que las estimulan". Sobre todo, este proceso es comprobado en la reversión masiva hacia los centros urbanos en el siglo XX, configurando una urbanización acelerada e intensiva, que ha tenido a la guerra social agraria como la estrategia instrumental que operó este vuelco.

Por otro lado, en cuanto a los conflictos ambientales y la configuración de "paisajes del riesgo y catástrofe" ${ }^{8}$, se puede afirmar que estos son la expresión espacial o testimonio explícito de las problemáticas estructurales de orden social históricamente determinadas (como se citó previamente), las cuales no han sido resueltas, como es la distribución y acceso desigual e injusto a la tierra, que somete a la población de menores recursos económicos y en estado de vulnerabilidad política a vivir en zonas de amenazas y estar expuestos a perder los pocos bienes materiales que poseen y hasta su propia vida.

En suma, al plantear que la planificación debe entenderse como una decisión política, se hace alusión entre otras consideraciones, a la justa valoración que esta merece por parte de los administradores públicos y de aquellos equipos de gobierno que asumen el ejercicio ejecutivo de dirección municipal, dado el peso que está tomando en diferentes 
ámbitos y grupos políticos las banderas y consignas de la libre intervención del mercado, sustentando así la idea-fuerza "de la poca necesidad del plan", por tanto, el ataque que recibe como instrumento idóneo para la construcción concertada, coordinada y orientada de un proyecto de sociedad inclusiva e incluyente. Esto indica que, en la actualidad, la planificación, la regulación legítima y necesaria de las actividades económicas en los tiempos modernos y aciagos del "dejar hacer, dejar pasar" representen paradójicamente un carácter progresista objeto de reacción.

Planificación flexible frente a coyunturas presentes y oportunidades de negocio, versus, la planificación como construcción de una visión de futuro

Un tema central del debate, como se ha esbozado previamente, es la dicotomía existente entre dos enfoques de la planificación territorial que han entrado en fuerte disputa y contradicción ideológica-metodológica, como son: la "planificación flexible para el corto plazo" y el "plan o proceso planificador como productor de una imagen objetivo y visión de futuro para el largo plazo".

El primer punto de vista se sustenta en la respuesta inmediata que exigen los cambios vertiginosos y la transformación efervescente de la realidad territorial contemporánea. Los criterios rectores de esta postura son los altos costos de oportunidad que supone no tomar decisiones rápidas, la eficiencia y la capacidad de adaptabilidad constante que debe tener un territorio ante las circunstancias, retos permanentes y posibilidades que marca el sistema económico actual de la sociedad global-informacional, de negocios multinacionales y territorios en red.

La segunda perspectiva sitúa sus bases y pilares en que por antonomasia planificar significa interpretar los contextos, prever las tendencias (con o sin plan), reconocer los procesos y elementos estructurantes del sistema territorial en diferentes escalas espacio-temporales, y a partir de esto, construir posibles escenarios consensuados y convergentes de las máximas aspiraciones del conjunto y formación social.

De esta manera, no es preciso y pertinente rotular o adjetivar la planificación como "flexible" en razón a que en sí mismo el proceso planificador contempla y afronta los problemas inmediatos, dicho de otro modo, en palabras de Indovina (2004, p. 2):

[...] es políticamente irresponsable y técnicamente inconsistente dejar los problemas del presente para el futuro: el problema de la vivienda no se puede resolver de aquí a diez años, una vez desarrollado el plan, ni el tránsito de aquí a veinte años. Planificar es afrontar los problemas del presente con una perspectiva de futuro, y no dejar para el futuro aquello que es 
de hoy, ni condicionar el futuro con una solución fruto de la inmediatez del presente. La relación entre el hoy y el futuro es otro aspecto importante del planeamiento en un contexto de transformaciones aceleradas. Si los procesos de cambio son muy rápidos, la relación entre el hoy y el futuro se convertirá en un problema difícil.

De ahí que, construir y perseguir una visión de futuro no supone obviar, rehuir y postergar las urgencias y demandas del hoy, todo lo contrario, al enfatizar en políticas públicas de largo aliento (vivienda, infraestructuras, transporte público y movilidad, equipamientos colectivos, plataformas territoriales para la generación de empleo sostenido, etc.) la concreción de estas depende ineluctablemente del cumplimiento de un número de acciones acometidas en diversos momentos (el presente, el mediano y el largo plazo), como también de un proceso coherente y consistente de seguimiento y ajuste.

Por otra parte, como caso típico de las confrontaciones que surgen en el ejercicio de la planificación territorial y entre quienes representan la defensa y tutelaje de ciertos puntos de vista, se observa lo acaecido en la arena técnica y política catalana. En primer lugar, se destaca en palabras de Fernando de Terán (citado en Serra, 2009, p. 17):

[...] el crispado debate que hubo a principios de los ochenta entre los partidarios del proyecto (que encabezó en Barcelona Oriol Bohigas, antes antagonista y ahora autor del prólogo de su último libro) y los del plan, en los que se incluirá él mismo, no se ha acabado de cerrar. Para algunos era posible hacer urbanismo sólo a través de la arquitectura, para otros se precisaba una planificación previa a gran escala. Las posiciones se han acercado mucho. Pero si en los ochenta era Madrid la que defendía el plan y Barcelona el proyecto, ahora parece que sucede lo contrario. Cataluña está a punto de cerrar su plan territorial mientras que en Madrid está parado porque desde la comunidad se defiende el liberalismo de la mínima intervención".

En segundo término, como muestra de los contradicciones que surgen entre las metas de largo plazo del Plan Territorial Catalán ${ }^{9}$ y la inmediatez de la "mínima intervención" propia del neoliberalismo y el afán de lucro de la inversión multinacional, se exhibe la polémica propuesta del "megaproyecto Eurovegas", que intenta replicar este modelo de ciudad del ocio norteamericano en territorio español ${ }^{10}$, contando con el apoyo y beneplácito de la nueva administración de la Generalitat de Catalunya $^{11}$ (véase Figura 1). 
Sin lugar a dudas, este proyecto impopular pone en entredicho los principios y criterios adoptados en el Programa de Planeamiento Territorial del año 2004, en el cual se suscribía de manera consensuada el propósito de proveer instrumentos para corregir las tendencias a la dispersión, la especialización y la segregación de la urbanización a escala supramunicipal; en otras palabras, la búsqueda de un modelo de ocupación del territorio caracterizado por "la compacidad, la complejidad y el carácter integrado de los asentamientos, principal garantía de la preservación del suelo no urbanizado y del paisaje" (Acord per a un Govern Catalanista i d'Esquerres, p. 64, citado en Nel.lo i Colom, 2010, p. 138). Así pues, de acuerdo a la reflexión planteada sobre el papel de la política por Oriol Nel.lo i Colom (2010, p. 163-164), secretario para la planificación territorial del gobierno de la Generalitat de Catalunya durante el período 2003-2011:

El futuro del planeamiento territorial depende, claro está, de la voluntad política de darle vida y aplicarlo de manera efectiva. Así, su existencia está vinculada a la relación de fuerzas entre los intereses particulares y el esfuerzo colectivo para ordenar el territorio de forma sostenible, eficiente y equitativa. De forma inmediata, este esfuerzo colectivo deberá confrontarse con dos tipos de presiones: por una parte, la pulsión desreguladora amparada en el argumento de la simplificación de los procedimientos administrativos y la crisis económica; $y$, por otra, aquel municipalismo que responde, ante todo, a la propensión de ceder a los intereses particulares. Frente a esto habrá que recordar, una vez más, que las raíces de la crisis actual se encuentran, en buena medida, en la desregulación excesiva de los mercados y que el interés particular tiene sus límites en el bienestar colectivo.

Incluso, sobre este tipo de divergencias entre unos técnicos que defienden la filosofía y esencia de la planificación territorial como apuesta por una visión de futuro, a otra mirada que pone el acento en las voluntades políticas del "proyecto", o las ventajas de la "flexibilidad" en contra de la supuesta "rigidez" del plan director, hacía mención Joaquim Nadal i Farreras ${ }^{12}$, destacado historiador, exalcalde de Girona y Consejero de Política Territorial y Obras Públicas de la Generalitat entre los años 2003 a 2010, durante una intervención realizada en la Universidad de Barcelona, titulada "La planificación territorial en Cataluña en los inicios del siglo XXI"13.

En consecuencia, estos giros y reorientaciones lo que indican es la incidencia y protagonismo que viene cobrando la planificación posmoderna, que reivindica por un lado, el mercadeo o neo-branding territorial, las actuaciones puntuales y las operaciones de fragmentos espaciales, y soslaya, de otra parte, el análisis de conjunto, la necesaria reflexión en perspectiva de totalidad y la visión de largo plazo, todo ello, 
justo en el momento actual de desregulación y privatización de los servicios y bienes colectivos de la sociedad. Es así como bajo el paradigma de gestionar los "problemas locales, las posibilidades y oportunidades territoriales" con estrategias claramente homogeneizadoras, están emergiendo unos "paisajes comunes y lugares globales", tal como lo ha denominado de manera precisa el geógrafo español Francesc Muñoz (2008) en su obra Urbanalización ${ }^{14}$.

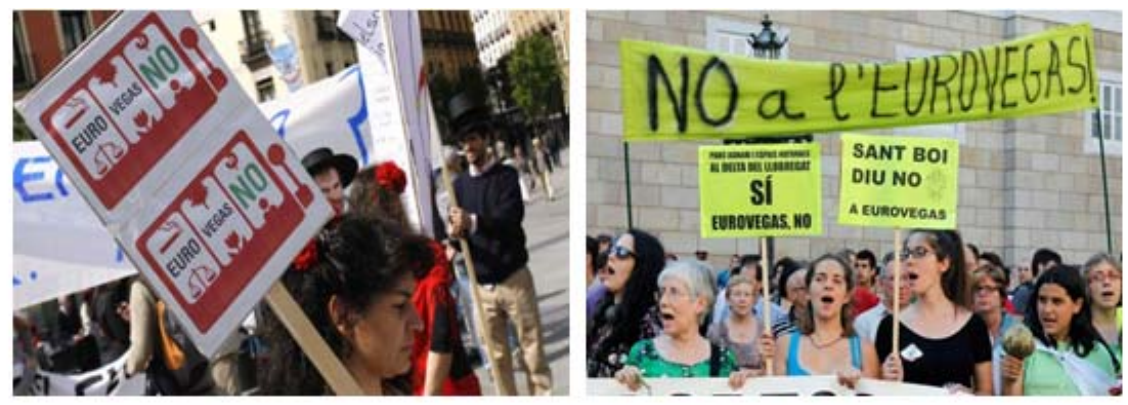

Fuente: Periódico 20 minutos. es: http://cdn.20minutos.es/img2/recortes/2012/05/23/61895-944. 550.jpg?v=20120802144016; Diario ya.es: $h$ ttp://www. cliarioya.es/store/bama\%20contra\%20eurovegas.jpg

Figura 1. Plataformas ciudadanas y movimientos sociales en contra del megaproyecto "Eurovegas" en España.

La necesidad de un análisis territorial de hermenéutica de procesos más allá de la habitual descripción de las transformaciones espaciales

Otro aspecto de enorme significado y necesaria inserción en el trabajo de la planificación territorial, es el relacionado con el análisis holístico, integrado e interpretativo de los procesos socio-espaciales. Sobre este método de trabajo técnicoacadémico, Francesco Indovina (2004, p. 3) ha hecho un persistente llamado de atención a los planificadores para que concentren sus esfuerzos analíticos en la "comprensión de los procesos que hay en juego en medio de los cambios territoriales" y en dar respuesta a inquietudes como: ¿qué elementos y relaciones los configuran, cuáles son las fuerzas y las tensiones que se producen?, y de esta forma ser realmente operativos y útiles en la búsqueda de soluciones a los problemas sociales y ambientales.

En este orden de ideas insiste en cultivar en "nuestra disciplina territorial" una nueva cultura de estudio de la realidad compleja, que supere la descripción simple y fragmentada que ha sido habitual en los diagnósticos del sistema territorial. Decisivamente, y coincidiendo con dicha intencionalidad, pero desde la función del urbanismo, Fernando de Terán (citado en Serra, 2009, 16) declara que:

[...] el urbanista del futuro tendría que ser una mezcla de ingeniero capaz de ver las infraestructuras necesarias en un territorio, un geógrafo que proporcione la visión analítica de cómo se organice éste y seguramente un 
arquitecto que sea capaz de proyectar y pasar a la acción $[\ldots]{ }^{15}$

A la par, el sociólogo, geógrafo y urbanista catalán Jordi Borja ${ }^{16}$, conocido por su papel determinante en el desarrollo y concreción de las políticas públicas de urbanismo social en Barcelona durante su etapa como teniente de alcalde entre 1983-1995, además de su vinculación y compromiso activo con los movimientos vecinales y ciudadanos en la búsqueda permanente de la integración e inclusión social ${ }^{17}$, expuso en su reciente lectura de tesis doctoral en la Universidad de Barcelona, titulada "Revolución urbana y derechos ciudadanos" ${ }^{18}$ que:

[...] en los años noventa, reconozco (la autocrítica hace parte de mi educación política) prioricé la dimensión positiva de la ciudad, influenciada especialmente por mis doce años en el gobierno de Barcelona, y luego, a partir del cambio de siglo recuperé el "método dialéctico" (perdón por la presunción) para centrarme en las contradicciones de los procesos urbanos $[\ldots]$. $^{19}$

Con esta exposición de ideas, Borja enfatiza en la importancia de un acercamiento al análisis de los aspectos contradictorios de la revolución urbana desde un enfoque y visión histórica que permita la interpretación de aspectos entramados y vinculados en la realidad, como son, por una parte, la optimización de la libertad del trabajo, el espacio y la formación, y de otro, la ampliación de la segregación, la insostenibilidad ambiental y la destrucción del capital fijo. Igualmente, esta perspectiva crítica y de hermenéutica de los procesos urbanos se evidencia en su exégesis sobre la relación entre el espacio público y los movimientos sociales en la lucha colectiva por el derecho a la ciudad, eje principal de su reflexión en los últimos años ${ }^{20}$.

Ahora bien, alrededor de esta aproximación holística, interesada en el estudio de los procesos y dinámicas históricas, es imprescindible señalar también el análisis realizado por el reconocido geógrafo español Horacio Capel sobre el urbanismo de la ciudad capital de Cataluña, al advertir los cambios en la gestión, criterios y principios del mundialmente conocido "modelo Barcelona", desde sus primeros postulados hasta su desarrollo actual. En especial, indica cómo el enfoque de los años ochenta se distinguió por adelantar acciones y actuaciones para mejorar espacios públicos que estaban en un proceso continuo de deterioro (arreglo de calles y plazas) al igual que el propósito por superar los problemas sociales y urbanísticos de los estratos de menores ingresos (algunas áreas periféricas), etc.

Durante esta fase inicial del modelo, fue relevante para su éxito, la participación ciudadana de los diversos movimientos sociales en la perspectiva de lograr ciertas reivindicaciones; para ello, fue propicio el ambiente político de la época, en tanto lideraban 
la administración municipal partidos políticos progresistas que hacían parte de las resistencias en el franquismo, y que en aquel momento de la transición democrática, estaban motivados para cumplir con la gestión de sus proyectos de equidad social. Luego, con el devenir de los años noventa, la ascensión y universalización del neoliberalismo, la competitividad local por nuevos mercados mundiales, entre otros factores, el modelo cambia sus objetivos, y por tanto, sus estrategias, formas de actuación y la espacialidad de estas. El interés de la ciudad por ser visible en el contexto mundial la ha llevado a olvidar sus intenciones sociales, el diálogo fiel con sus habitantes, y por otro lado, pasó de actuaciones puntuales (escala de barrio) a los grandes eventos y proyectos. Como lo afirma Capel (2007, p. 28-31):

\begin{abstract}
La obsesión por convertir la ciudad en un polo mundial, en atraer visitantes y posibles inversores es perversa $y$, finalmente, contraproducente: acaba por olvidarse de los ciudadanos que viven cotidianamente la ciudad, y que reaccionan contra ese olvido, contra la falta de equipamientos de barrio, contra la arquitectura espectacular e irresponsable, contra el arrasamiento del patrimonio construido, es decir de la memoria histórica, que realizan los mismos que se llenan la boca retóricamente de alusiones a la identidad y al pasado.
\end{abstract}

Siguiendo estas consideraciones, es posible inferir el desafío que debe, y de hecho está enfrentando la sociedad de Barcelona para asumir las consecuencias de la ejecución del modelo durante más de veinte años. Las tensiones entre el espacio cotidiano del ciudadano (local) y el escenario "simulacro" del turista de esta ciudad global se superarán en la medida en que se entienda esta dinámica, y a su vez, se tomen las medidas pertinentes para que se mitiguen y controlen sus efectos perversos ${ }^{21}$.

En relación con lo anterior, uno de los geógrafos más influyentes de los últimos treinta años, David Harvey, aborda desde los conceptos de capital simbólico y marcas de distinción ${ }^{22}$, la elucidación sobre cómo Barcelona se ha posicionado dentro del sistema europeo de ciudades, llegando a encontrar un éxito inicial a través de una mezcla de estrategias centradas en la mercantilización de su cultura, iconos artísticos y estilos de vida, como también en las diversas inversiones multinacionales y operaciones urbanísticas que son el nuevo sello del paisaje urbano de las ciudades globales ${ }^{23}$. Verbigracia de estos elementos de intervención, en el libro de Harvey y Smith, titulado "Capital financiero, propiedad inmobiliaria y cultura (2005, p. 49-50) Harvey precisa lo siguiente:

Las últimas fases de urbanización de la zona portuaria parecen exactamente iguales a otras 
cualesquiera del mundo occidental, la increíble congestión del tráfico provoca presiones a favor de construir bulevares que atraviesen determinadas zonas de la parte antigua de la ciudad, las grandes tiendas multinacionales sustituyen a las tiendas locales, la renovación de antiguos barrios obreros provoca el desplazamiento de antiguas poblaciones residenciales y destruye el tejido anterior, y Barcelona pierde algunas de sus marcas de distinción. Se producen incluso síntomas nada sutiles de disneyficación. Esta contradicción viene marcada por interrogantes y resistencia. ¿Qué memoria colectiva se celebra aquí? ¿La de los anarquistas, como los icarianos, que desempeñaron un importante papel en la historia de Barcelona? ¿La de los republicanos que combatieron tan fieramente contra Franco, la de los nacionalistas catalanes, la de los inmigrantes andaluces o la de un viejo aliado de Franco como Samaranch? ¿Qué estética es la que realmente cuenta: la de los tremendamente vigorosos arquitectos de Barcelona, como Bohigas? ¿Por qué aceptar cualquier tipo de disneyficación?

En breve, son esta clase de cuestionamientos y formas de indagar, examinar y actuar en la planificación territorial y urbanismo las que son ineludibles a la hora de afrontar el reto de la construcción de la "ciudad democrática".

\section{El conflicto como elemento estructurante del análisis territorial y la toma de decisiones en los procesos de planificación con participación ciudadana}

A pesar del temor que usualmente revisten los diferentes conflictos sociales a enfrentar por los equipos de planificadores, estos deben ser entendidos como aspectos proactivos y potenciadores de la elaboración y gestión de planes incluyentes. Por eso al invertir la carga negativa que se asocia a ellos, se reconoce la importancia de un plan participativo y con alto valor pedagógico, de modo que los técnicos y administradores públicos deberían ver de otra manera los conflictos ocurridos entre los diversos grupos sociales porque ellos facilitan "visibilizar a todos los ciudadanos, hace que se escuche lo que piensa la gente, permite conocer cuáles son sus anhelos y necesidades sentidas".

Sobre este aspecto, a partir de las contribuciones y aportes de Indovina $(2004$, p. 4) se puede señalar que el plan es cíclico, cierra conflictos pero abre constantemente otros, ya que consiste en una discusión y negociación de múltiples intereses contrapuestos, y por ello propende como filosofía de actuación "al máximo equilibrio, equidad y redistribución". 
De igual modo, así como es preciso superar la carga y significado negativo asignado al conflicto en el ejercicio de la planificación, es imperioso su uso legítimo por parte de las organizaciones comunitarias, vecinales y cívicas en el momento de poner en acción la lucha social por la reivindicación de los derechos ciudadanos y el cabal cumplimiento del Estado en la cobertura (de calidad y en la cantidad requerida) de los servicios y bienes sociales, como son, entre otros, los equipamientos colectivos ${ }^{24}$, el espacio "público" y un ambiente saludable y sustentable para toda la población ${ }^{25}$, etc.

Es más, en la actualidad, es urgente y vital la asociatividad vecinal y la movilización social como expresión colectiva de resistencia ante la irrupción y dominio generalizado de la apropiación especulativa del espacio, como se puede constatar de la generación de enormes capitales (concentrados en pocas personas y gremios) a través de la participación activa del sector financiero en la producción residencial y urbana (utilizando como mecanismos los prestamos de usura y la cogestión en la propiedad y tenencia del suelo), lo que ha ocasionado la crisis económica actual de escala planetaria.

A su vez, este proceso de acumulación rentista en la ciudad neoliberal contemporánea (perfeccionada con la re-ingeniería financiera) tiene como contracara la desposesión o expulsión de la población de ingresos bajos y medios de los barrios tradicionales y populares, debido a la presión económica que produce este mercado territorial con estrategias como la gentrificación inmobiliaria y la híper-valoración del suelo en sectores de la ciudad estratégicamente ubicados por su centralidad o el interés de inversiones futuras.

En síntesis, el valioso cambio de perspectiva en el trabajo y percepción de los técnicos alrededor del concepto de conflicto debe ameritar también una transformación profunda en la planificación territorial y la gestión urbana de los problemas sociales, naturales y/o ambientales, vinculando e integrándose activamente con los colectivos sociales para que realmente tengan sentido y resultados positivos los procesos de participación y concertación ciudadana en el desarrollo de la construcción de una imagen territorial integradora, concebida para la producción social de un territorio democrático, es decir, con el concurso entusiasta, dinámico y continuo de toda la comunidad.

\section{La planificación territorial como garante de la sustentabilidad y la democratización en el uso del espacio}

El plan territorial al propender por la construcción de imágenes objetivo de largo aliento para el espacio vital de diversos tipos de comunidades, debe sustentarse en unos principios, premisas y criterios que orienten e inspiren las políticas públicas y directrices encausadas al logro de las metas prospectadas.

En Cataluña, por ejemplo, con base en las explicaciones ofrecidas en el seminario "Planeamiento territorial: análisis de 
casos", orientado en la Universidad de Barcelona en el año 2010 por técnicos de reconocida trayectoria en la Generalitat de Catalunya, como Ferran Miralles ${ }^{26}$, coordinador de Evaluación Ambiental Estratégica para la Planificación Territorial, Joan Fortuny Castellet ${ }^{27}$, coordinador de Planes Territoriales, y Juli Esteban i Noguera ${ }^{28}$, director del Programa de Planificación Territorial del Departamento de Política Territorial y Obras Públicas, se identificó como principio básico y criterio sustantivo del Plan Territorial General "la necesidad de moderar el consumo del suelo".

Justamente, fundamentados en esta elemento rector de la política territorial es que se pueden llevar a la práctica las premisas de protección especial de áreas de interés natural, patrimonial y cultural, como también los fines de cohesión social, compacidad o densidad urbanística con calidad y la cobertura universal de todos los servicios requeridos por la población. En esta línea programática juega un rol esencial el proyecto de consolidar la "ciudad compacta", evitando así la dispersión urbana que se ha propagado con gran celeridad en la costa mediterránea y algunas zonas de las comarcas del interior de la comunidad autónoma, fenómeno que ha ocasionado como efecto colateral las lesivas consecuencias al medio ambiente y a la socialización de las personas que viven en los espacios de auto-exclusión y aislamiento de los conjuntos residenciales rururbanos (véase Figura 2 y 3 ). 


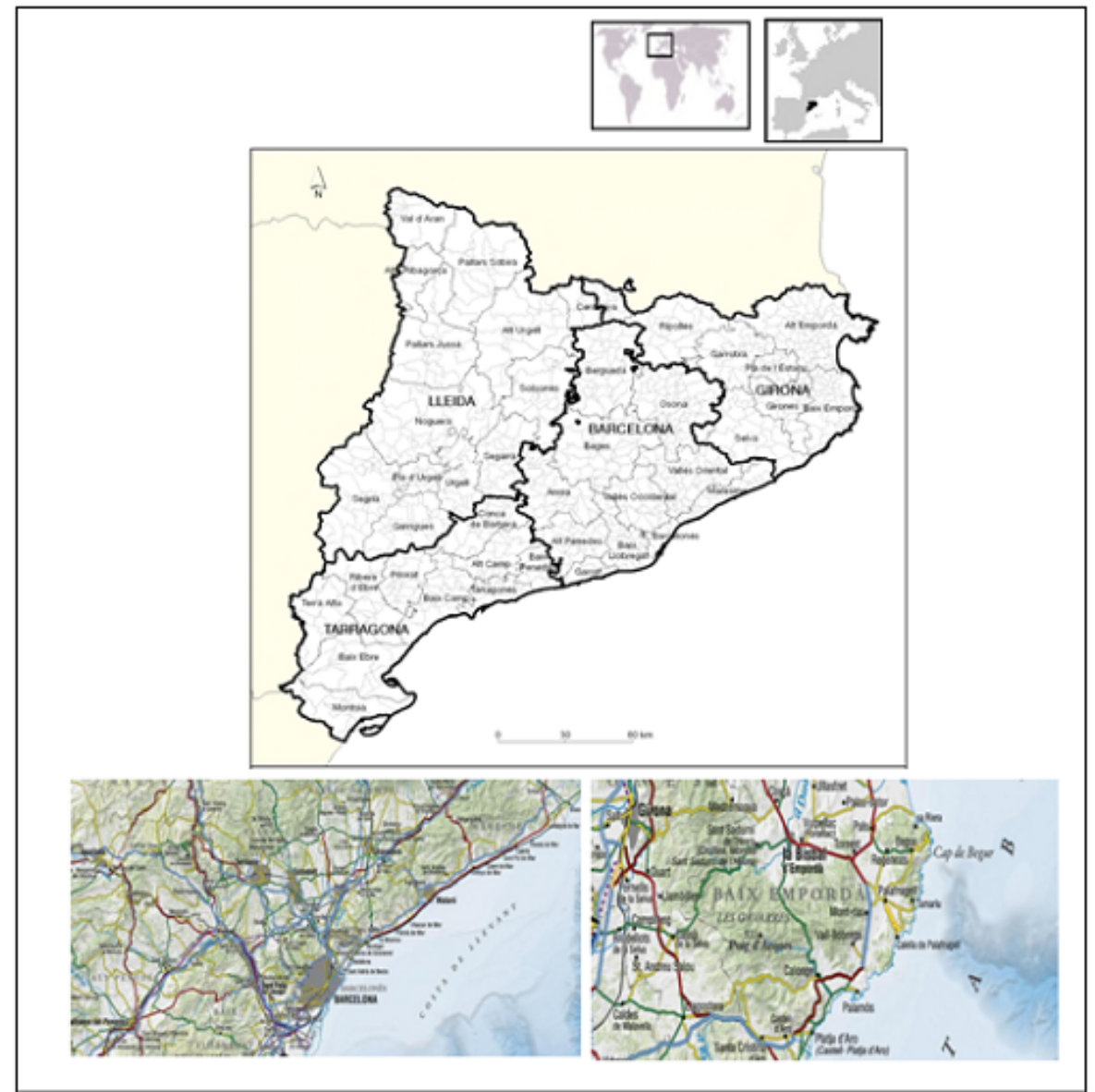

Fuente: Institut Cartogràfic de Catalunya (ICC): http://www.icc.caticat/

Figura 2. Localización geográfica de Cataluña, España. Delimitación por demarcaciones, comarcas y municipios. Casos: Vallès Occidental y Baix Empordà. 


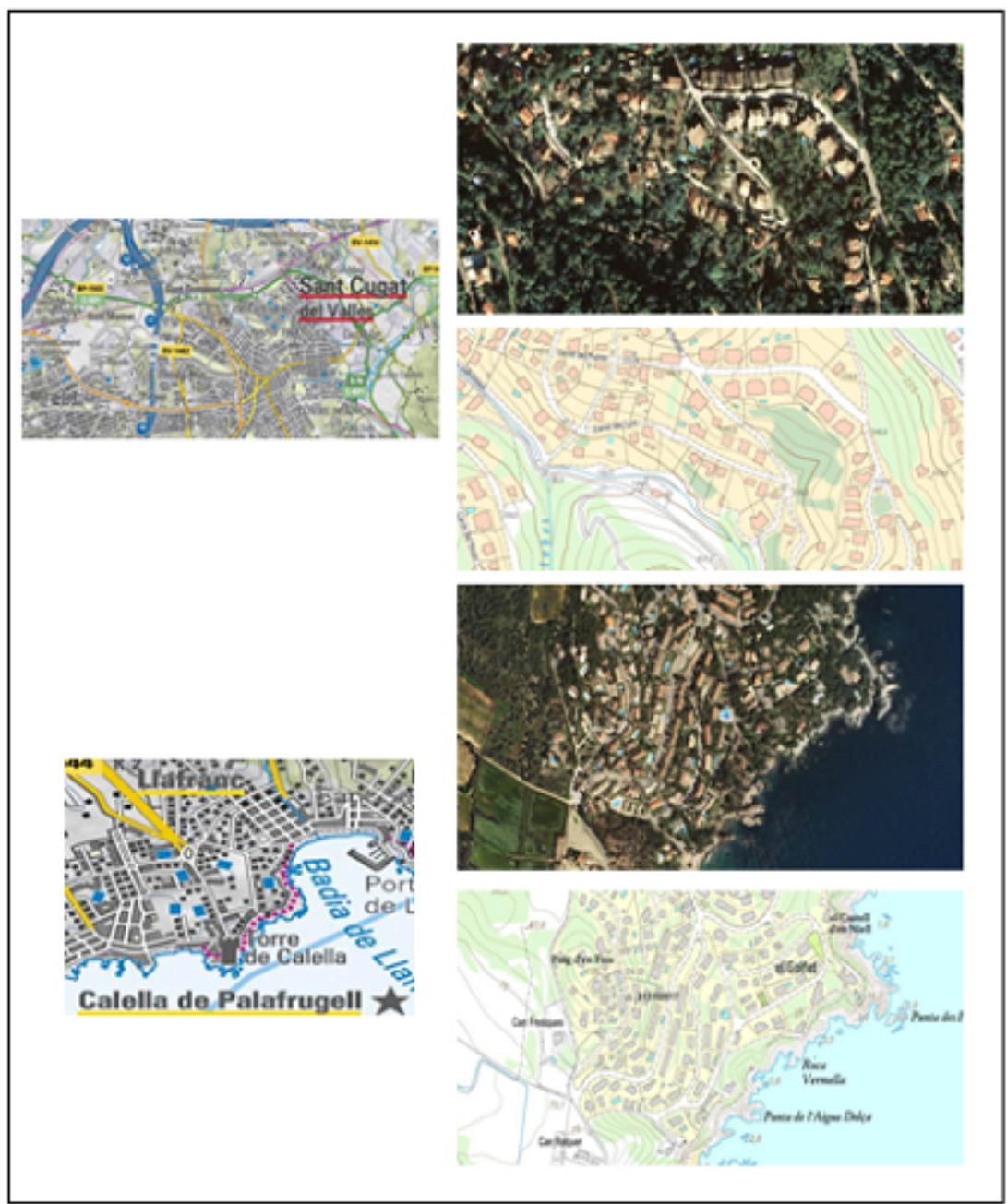

Fuente: Institut Cartografic de Catslunya (CC) htto:/Awwwico.cativissir3

Figura 3. Expansión del urbanismo disperso en Cataluña. Casos: Sant Cugat del Vallès (Comarca del Vallès Occidental-Barcelona) y Calella de Palafrugell (Baix EmpordàGirona).

Precisamente, es alrededor de este tipo de dinámicas que la planificación territorial debe ejercer un papel protagónico, no obstante, es conveniente reconocer las limitaciones que enfrenta, en la medida que el modelo de urbanización copartícipe y corresponsable de la crisis económica y social a la que asistimos actualmente está gestado y operado por actores y fuerzas que superan la buena voluntad y capacidad de los técnicos comprometidos con un proyecto social, ciudadano y urbano de igualdad e integración.

En este orden de ideas, a partir del planteamiento formulado por Jordi Borja en su lectura de tesis, en relación a que "urbanizar no es ciudad", se abre un debate sobre las características del desarrollo urbano especulativo y en contra de una de sus expresiones más elocuentes, como es la ciudad difusa, dispersa y segregada, constituida en enclaves e islas fragmentadas que configuran regiones urbanizadas sometidas a la ciudad, pero en la cual las personas que residen allí no tienen 
la condición o cualidad de ciudadanos, al no tener un gobierno que los represente, ni una historia que genere elementos de identidad y sentidos de pertenencia, arraigo, o la construcción de tejido social articulado por las tradiciones económicas y culturales barriales; por otro lado, en términos morfológicos es discontinua, adolece de límites, de una solución de continuidad y proximidad, en definitiva, por estas y otras razones, este proceso constituye en sí mismo la "negación de la ciudad".

Con todo, es posible aseverar que con la presencia global del modelo urbano de especulación arrollador, antidemocrático e insostenible, estamos siendo espectadores del paso frenético de la dimensión escalar definida por Jean Gottmann (1961) como megalópolis a la progresión planetaria prevista por Doxiadis y Papaioannou (1974) que dio lugar al concepto de ecumenopolis, proceso conducido a la velocidad que ha impuesto la voracidad de la ganancia esperada por el maridaje y connivencia de agentes público-privados en el contexto de la laxitud legal que exige, facilita e imprime el sistema de mercado de la vivienda de los Estados neoliberales.

Ciertamente, en atención al fenómeno acelerado de difusión urbana a un nivel superlativo en América Latina, hizo referencia la arquitecta argentina Sonia Vidal-Koppmann en el XII Coloquio Internacional de Geocrítica realizado en Bogotá durante el mes de mayo de 2012, con su trabajo sobre las "Ciudades privadas en la región metropolitana de Buenos Aires" (Vidal-Koppmann, 2012).

En este expuso las dificultades político-administrativas, territoriales y de gobernabilidad para la gestión local que ha generado la expansión urbana ocurrida desde la década de los noventa con el desarrollo de los mega-emprendimientos inmobiliarios (denominados por el marketing urbano como "clubes de campo, barrios cerrados, ciudades-pueblo, miniciudades", etc.), proceso "no planificado y de alta complejidad", tal y como lo han definido diferentes investigadores del crecimiento de las metrópolis latinoamericanas (PrévôtSchapira, 2002; Ciccolella, 2004; De Mattos, 2004; entre otros) (Vidal-Koppmann, 2012, p. 2).

Como caso paradigmático de esta nueva dinámica de comercialización y producción inmobiliaria de "guetos de autoexclusión periurbanos"29, se identifica la primera localidad privada de Argentina, Nordelta, la cual ha sido objeto de múltiples análisis y discusiones (Janoschka, 2000, 2002a, 2002b, 2003; Prévôt-Schapira, 2000; Torres, 2000, 2001; Svampa, 2001; Vidal-Koppmann, 2001, 2002, 2010; Janoschka \& Borsdorf, 2005; etc.) en razón a su dimensión y evidente impacto territorial al convertirse en centralidad "excluyente" del municipio de Tigre, en clara competencia con su centro tradicional, al igual que por despertar el interés de hacer posible en estas latitudes la consolidación del ciclo evolutivo de las comunidades cerradas (gated communities) con la conformación de municipios privados, a semejanza de lo que ha 
sucedido en Estados Unidos, y que magistralmente ha calificado Evan McKenzie ${ }^{30}$ (1994) como "Privatopia".

Para terminar, reconociendo el panorama urbano actual y el desafío futuro para la construcción de una ciudad democrática, sustentable y con equidad, se hace imperativo avanzar en un ejercicio público, abierto y participativo de planificación territorial que contemple como elementos imprescindibles la regulación y control del uso del suelo urbano, las veedurías ciudadanas con carácter vinculante y un trabajo ético y responsable por parte de los funcionarios que asuman la alta dignidad de dirigir la administración municipal, de modo que con la articulación de estos aspectos se pueda frenar y eliminar progresivamente la especulación inmobiliaria consustancial a la exacerbación urbanística neoliberal.

\section{Aplicar los postulados del desarrollo social con una perspectiva territorial}

Otra actividad a tener en cuenta en la planificación territorial, es el diseño y puesta en marcha de políticas públicas de desarrollo social que consideren objetivamente sus requerimientos e implicaciones espaciales reales ${ }^{31}$. Para el caso colombiano, ha sido común desde el ejercicio institucional la aprobación de planes de desarrollo local, regional y nacional carentes de un enfoque geográfico, siendo esta una razón de su limitada efectividad.

En tal sentido, si bien en un primer estadio del "proceso de modernización" ${ }^{32}$ (1930-1960) se erigió una política de planeación regional que priorizó el desarrollo del sector primario extractivo como estrategia para alcanzar altos niveles de crecimiento económico a partir de la explotación y manejo de los recursos naturales ${ }^{33}$, posteriormente se ha adelantado una variedad de programas de gobierno consignados en los respectivos planes nacionales de desarrollo ${ }^{34}$, que se han caracterizado por el tratamiento a-espacial de la política económica, o en otra palabras, sin contemplar sus repercusiones provinciales. 


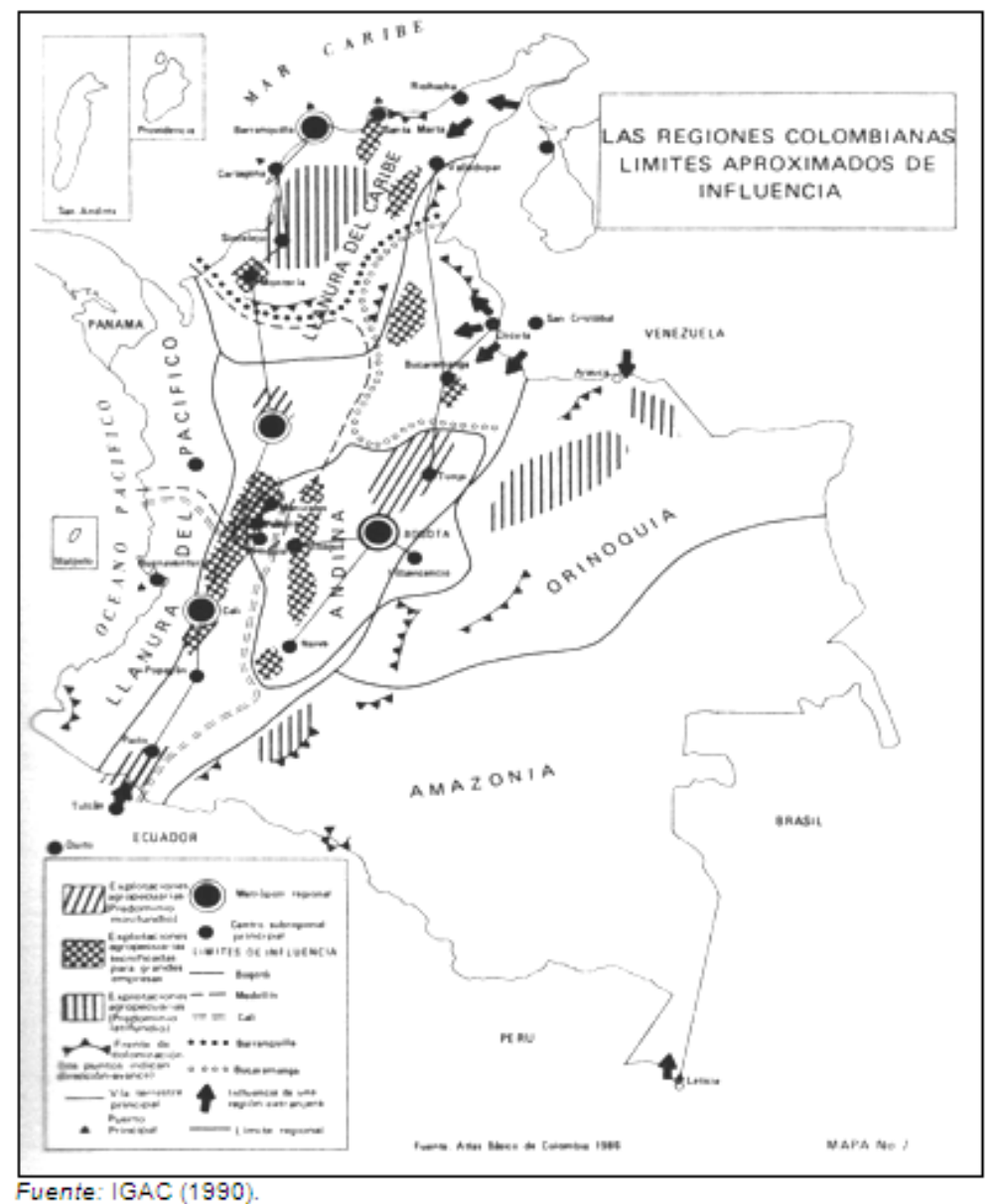

Figura 4. Las regiones colombianas, límites aproximados de influencia. Ȧreas geográficas de explotación agropecuaria.

Como muestra, en la década de los sesenta con la influencia del estructuralismo cepalino se continuó fomentando la política de industrialización vía sustitución de importaciones con el fin de reducir los desequilibrios socioeconómicos entre el campo y la ciudad, y entre las regiones "atrasadas vs. avanzadas", sin embargo, este impulso no produjo un cambio significativo en las tendencias de la distribución territorial del desarrollo.

Por el contrario, lo que se intensificó fue la situación predominante de un desarrollo espontáneo liderado por algunas regiones que reforzaron la primacía de las principales ciudades del país en el contexto de la articulación económica nacional con los circuitos globales de comercio exterior ${ }^{35}$, aprovechando sus ventajas comparativas al incorporarse a mercados internacionales de manera diferencial con base en actividades que ya habían sido rentables en otras latitudes, como son por ejemplo el caso de la industria azucarera en el valle interandino del departamento del Valle del Cauca, teniendo como epicentro a Cali (establecimiento del modelo del nordeste brasilero y del Caribe) y el café en las zonas de montaña (1000 a 2000 m de altitud) siendo el centro occidente colombiano el máximo exponente de la adaptación de este modelo agro-industrial y 
empresarial, exitoso en Centroamérica y Brasil (véase Figura $4)$.

Luego en las dos décadas siguientes (1970-1980), tras la desfinanciación del proceso de industrialización ${ }^{36}$ y el posterior endeudamiento estatal asumido con la banca multilateral para proporcionarle continuidad a esta política económica ${ }^{37}$, lo que provocó a la postre la denominada "década perdida", de los tímidos esfuerzos realizados para impulsar la descentralización y el fomento de los polos productivos a escala local, se generó una crisis social de alcance nacional expresada en el incremento progresivo de las tasas de desempleo, las necesidades básicas insatisfechas (NBI) y la línea de pobreza (LP), como también a nivel institucional, manifestado en la reducción de las partidas presupuestales y recursos económicos para el funcionamiento de las corporaciones de desarrollo o el desmonte final de las Consejos Regionales de Planificación, CORPES ${ }^{39}$ (véase Figura 5).

Más tarde, con el devenir del neoliberalismo como doctrina hegemónica de la política económica nacional desde la década de los noventa, y a partir de sus pilares ideológicos de fuertes derechos de propiedad privada individual, el imperio de la ley en beneficio de las "libertades empresariales" -las instituciones del libre mercado y del libre comercio-, junto a la masiva privatización de activos del Estado y la desregulación de los diferentes sectores económicos (Harvey, 2007) ${ }^{40}$, en el país se ha radicalizado una agenda de desarrollo territorial definida por las fuerzas del mercado y los intereses monopólicos de empresas internacionales, generando un incremento exponencial de la expoliación de los recursos naturales, en particular, de los no renovables, como es el caso de los minerales y el petróleo.

Así pues, la configuración de los espacios de producción y extracción en el proceso de re-primarización de la economía colombiana, evidencia la anarquía territorial derivada de la supresión de los instrumentos legítimos y necesarios de gestión, control y regulación por parte del Estado para el desarrollo de dichas actividades (aranceles, ajustes fiscales punitivos, la planificación y los controles ambientales, así como impedimentos localizados) (Harvey, 2007, p. 75), todo ello para permitir la "libertad de movimiento" del capital a favor de un proyecto de restauración o recomposición de élites corporativas y financieras multinacionales que se sustentan en la repatriación de sus ganancias o plusvalías, producto de las ventajosas posibilidades de inversión y operación en países en desarrollo (débil legislación, flexibilidad laboral, etc.) impuestas políticamente por instituciones como el Fondo Monetario Internacional y el Banco Mundial. 


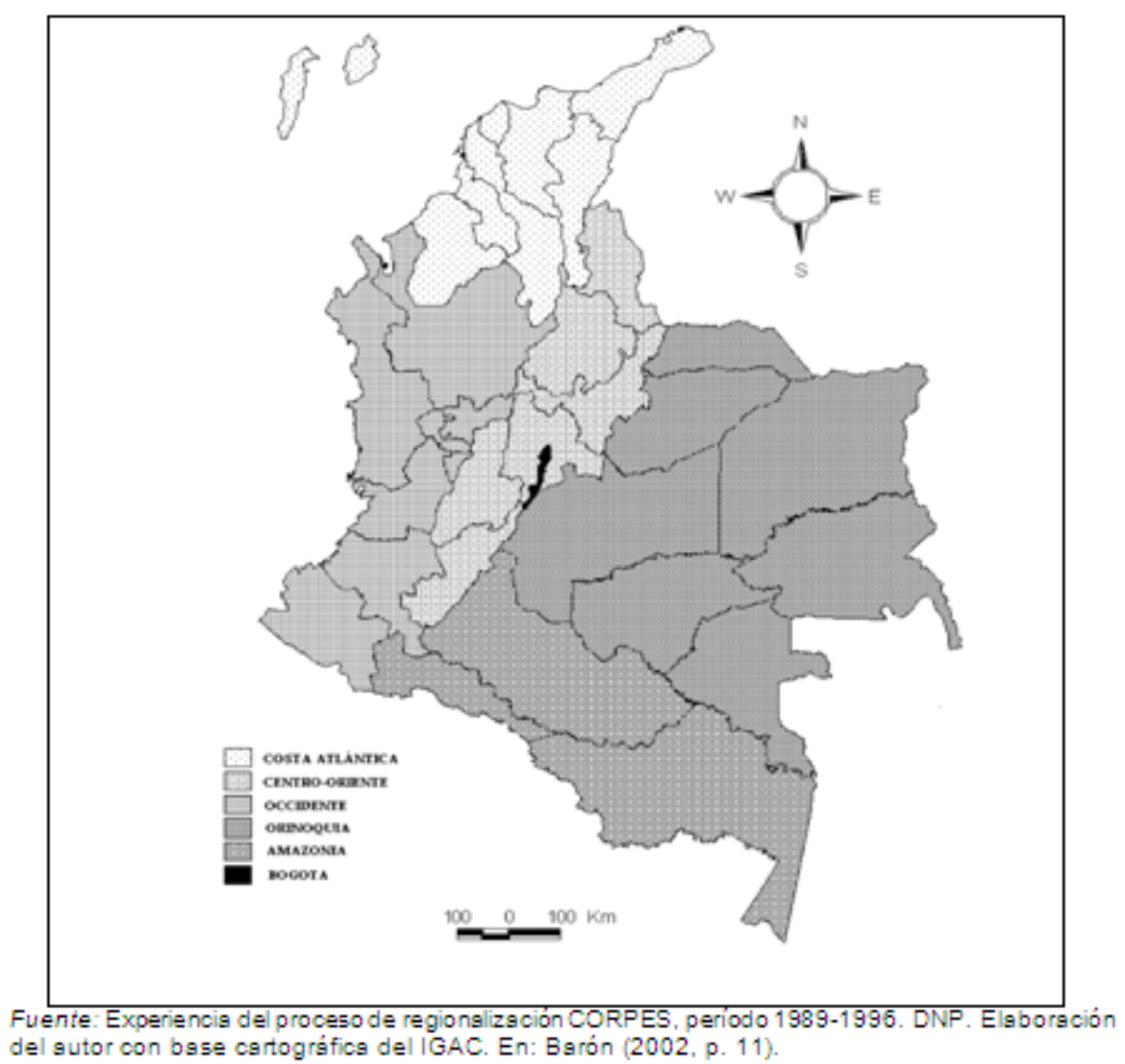

Figura 5. Regionalización en Colombia, CORPES.

En efecto, al intensificarse este modelo de economía de enclave neo-colonial, con su estrategia de "acumulación de capital transnacional por desposesión nacional", se produce en consecuencia un saldo negativo para el país, en primer lugar, porque la soberanía estatal sobre el uso del territorio, la circulación de bienes, mercancías y capitales es entregada en una actitud servicial al "mercado global"; y en segundo término, porque va en contravía de la definición de un proyecto de desarrollo nacional con autodeterminación productiva, que respete la aptitud física del territorio y considere las potencialidades económicas de las comunidades regionales en función de sus tradiciones laborales ${ }^{41}$.

Por tanto, en representación de los efectos e impactos del régimen de inversión extranjera (concentración en el mercado externo-exportaciones y descuido del mercado interno), se presenta la multiplicación de proyectos mineros en áreas de gran fragilidad natural y/o en reservas de territorios indígenas

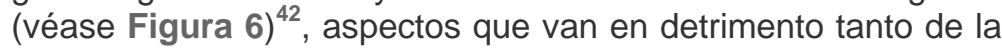
titularidad y gobernabilidad de las comunidades raizales sobre sus territorios ancestrales (concedida por la historia social y respaldada por la Constitución Política Nacional), como de la conservación de la biodiversidad y del patrimonio ambiental colombiano $^{43}$. 
Decididamente, como se puede observar en los objetivos y principales lineamientos del actual Plan Nacional de Desarrollo 2010-2014 "Prosperidad para todos", sus estrategias se inscriben en políticas benefactoras de los intereses financieros, en la competividad de las empresas privadas y el aumento de su productividad, entre otros aspectos que confirman cómo el Estado colombiano apuesta por cumplir un papel de intermediario y facilitador de la operación de los gremios económicos y el establecimiento de compañías multinacionales en el país. De ahí que, según lo estimado en el Plan Plurianual de inversiones casi la mitad de los rubros están destinados al pilar de Crecimiento Sostenible y Competitividad, con un $45,6 \%$; en resumidas cuentas, en distribución del gasto público el Estado colombiano invertirá alrededor de 221 billones de pesos de un total de 485 billones del presupuesto general de la nación para apalancar el sector privado (Sarmiento, 2011).

Más aún, como testimonio del modelo productivo neoliberal promovido por el gobierno nacional para atraer inversión extranjera, se reconoce que el $80 \%$ de ella se concentra en el sector primario (Sarmiento, 2011), lograda con su fórmula de: expoliación permisiva de los recursos naturales, reducción de impuestos, reformas fiscales y tributarias, abaratamiento de los costos de trabajo con la flexibilización de las condiciones laborales y políticas de protección a las multinacionales a partir de exenciones reduciendo todos aquellos costos que pueden ser onerosos para el capital. Así, en palabras de la politóloga colombiana Paola Salazar (2011, p. 5):

Sobresale de la proyección presupuestal la amplia importancia de las fuentes de financiación, sobretodo el segundo lugar ocupado por el sector privado con una inversión que asciende a $\$ 170,3$ billones. Entre estas inversiones se destacan las correspondientes a las locomotoras para el crecimiento y la generación de empleo, principalmente para la formalización minera y expansión energética (\$93,4 billones), Vivienda y Ciudades Amables (\$34 billones) y para Infraestructura de Transporte (\$16 billones). Esto permite visibilizar el importante papel del sector privado en la formulación y sostenibilidad del Plan de Desarrollo, lo cual se podrá rectificar en las distintas propuestas económicas y sociales presentadas por el Gobierno. 


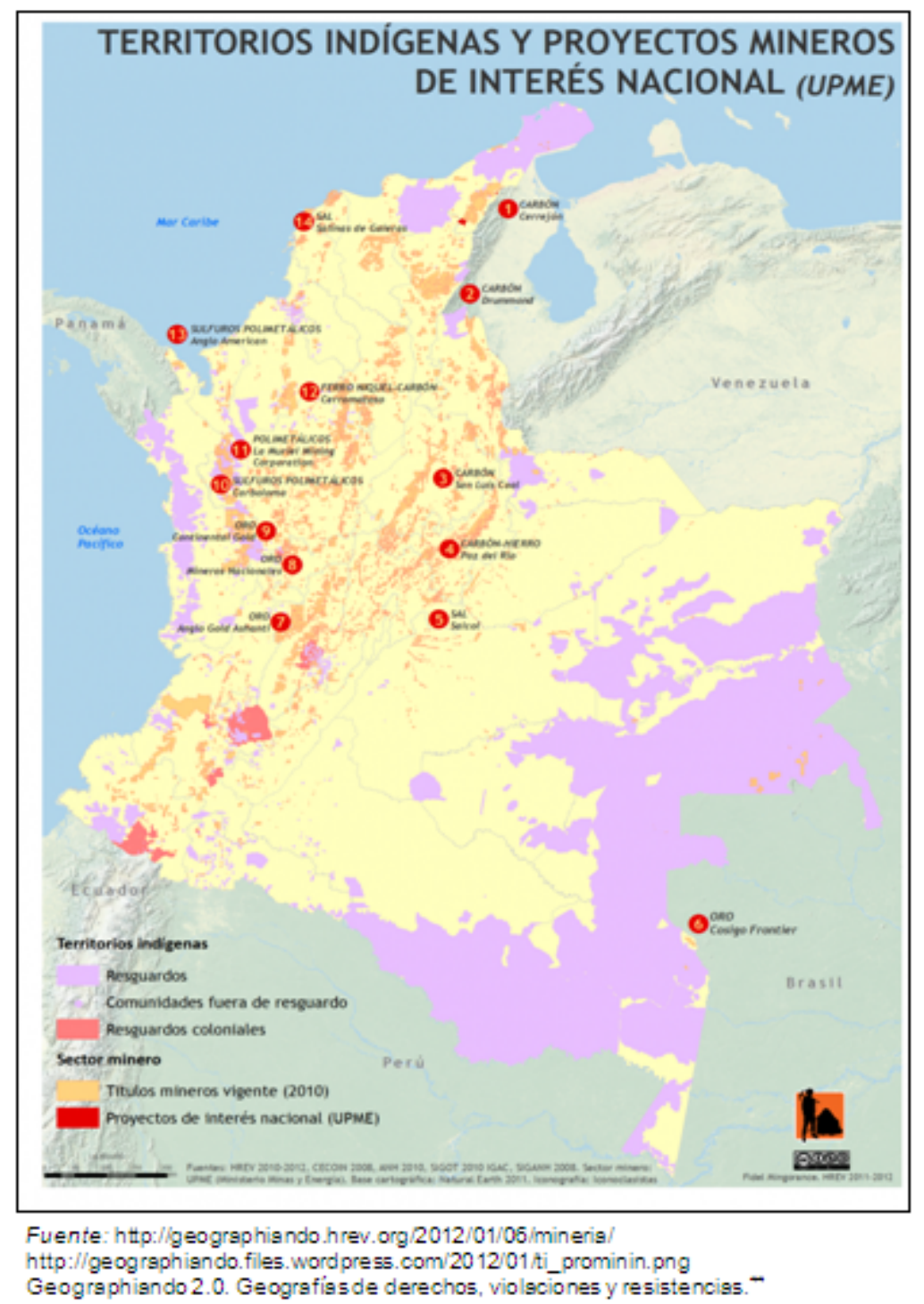

Figura 6. Cartografía de la desposesión nacional. Caso: Proyectos mineros.

Ciertamente, entre las propuestas destinadas al crecimiento económico se destacan por su peso específico las relacionadas con el sector minero energético, debido a la riqueza minera del país. Es así como la inversión extranjera directa pasó de USD\$3.637 a USD\$4.637 entre 2006-2009 teniendo un efecto incremental en las exportaciones, las cuales pasaron de USD\$13.145 a 19.677 de 2006 a 2009 (Salazar, 2011, p. 23).

Por añadidura, estas medidas son la evidencia de una estrategia que profundiza la acumulación capitalista so pretexto de favorecer el crecimiento económico. No obstante, dicha estrategia de acumulación privilegia un modelo de desarrollo que favorece la extracción de recursos naturales renovables y no renovables, principalmente el sector minero energético, pese a ser consciente del limitado impacto para el desarrollo del país. Adicionalmente, es un modelo orientado a la explotación de la biodiversidad en un discurso supuestamente dirigido a la protección de la diversidad y los grupos étnicos (Salazar, 2011, 
p. 39). En suma, como lo expone claramente Salazar (2011, p. 25):

Para el sector minero-energético se propone continuar con la política ya implementada, sin embargo, el Plan presenta una paradoja al reconocer la baja productividad o baja capacidad de generación de valor de los sectores extractivos. Al mismo tiempo en el gobierno se reconoce que esta estructura productiva y exportadora del país sólo genera beneficios en el corto plazo, puesto que "(...) si los ingresos generados por las exportaciones no se aprovechan para la investigación e innovación en productos de alto valor agregado, la oferta exportable será muy limitada en el momento en que se agoten las reservas de los recursos no renovables (...)". A pesar de todo, no se visualiza una propuesta de desarrollo distinta a la extracción de recursos naturales, por el contrario, toda la estrategia consignada en el sector se orienta a la atracción de la inversión privada (extranjera) principalmente para el aprovechamiento y explotación de los recursos naturales del país.

Empero, como alternativa a las políticas de "desarrollo" de carácter vertical agenciadas por el statu quo neoliberal, se viene construyendo en los últimos años desde la base y acción colectiva de los movimientos sociales una serie de propuestas de desarrollo territorial popular que tienen como objetivo la producción social de un espacio para la igualdad y la integración comunitaria, de manera que se puedan configurar ciudades y zonas rurales para "el buen vivir" y no para el capital, en las cuales los ciudadanos asuman el protagonismo en el ejercicio democrático de la toma de decisiones orientadas a la constitución del territorio cooperativo y de inclusión deseado $^{45}$.

En este sentido, se propone para su consecución la recuperación, aprendizaje y diálogo de saberes o experiencias con proyectos de larga tradición, como son, entre otros, los "Planes de Vida" de las comunidades indígenas y sus estrategias de armonización territorial. Igualmente, se considera como mecanismo dinamizador del mandato social para la construcción de un territorio con equidad, el desarrollo de un proceso de educación popular dirigido a la comprensión dialéctica de los problemas nacionales y al impulso del desarrollo comunitario.

Por último, se determina como elemento indispensable la convocatoria y realización de una reforma territorial (urbana y rural) participativa que tenga como principio axiomático el acceso justo a la vivienda y a unas condiciones de vida digna garantizadas por la prestación de los derechos sociales básicos 
y fundamentales que están consignados en la Constitución Política Nacional (educación, salud, etc.) ${ }^{46}$.

\section{Gestión para el desarrollo local con base en un enfoque endógeno y con criterio colectivo}

A raíz de la diferencia con lo enunciado por el economista y exministro de Planificación y Cooperación del Gobierno de Chile durante el período 2003-2004, Andrés Palma Irarrázaval ${ }^{47}$ en su texto titulado "Desarrollo Social y la Gestión Local" (2006, p. 2), al señalar que "en principio podemos tener la convicción de que el gobierno local concentra la gran posibilidad de atraer valores, principios y criterios propios de una globalización lo que puede tener una réplica particularizada y más concreta en el nivel provincial y comunal de nuestra actual división política y administrativa", creo sobre esta afirmación que, en cualquier caso, la evidencia empírica ha demostrado los amplios errores y desaciertos en estandarizar soluciones de la "globalización" a los problemas de naturaleza diversa que se presentan en los diferentes espacios geográficos locales del complejo mundo contemporáneo.

Claramente se viene presentando una tendencia a "copiar, imitar, transferir o adaptar" modelos exitosos de gestión local de diferentes latitudes y lugares a otros ámbitos o espacios municipales que en su historia y devenir carecen de coincidencias ciudadanas -culturales, políticas y económicascon el "territorio modelo"48, por tal razón, con algunas excepciones tienen cierta trascendencia, eficiencia y sostenibilidad en el tiempo, y por supuesto no pocas dificultades para su ejecución.

En realidad, suponer que en medio de esta última faceta de la globalización económica neoliberal sustentada en los principios y valores de la "competencia, la individualización y la especialización territorial", más allá de la complementariedad o asociación municipal, se va a generar el tan deseado desarrollo económico creciente, aparte de la sostenibilidad ambiental y la reducción de las desigualdades sociales, carece de sentido; ¿acaso es posible tanta ensoñación en medio de la vorágine especulativa y perversa que reside en la matriz de este sistema?; suponer y afincar esperanzas en estos preceptos es por la fuerza de los hechos, equivocado y precisamente "insostenible".

Por el contrario, se hace cada vez más ineludible aprovechar los recursos propios (capital social y cultural -tradiciones y formas de actuar, resistir y ser proactivos en épocas de crisis de toda índole, etc.-), para lo cual se deben tener en cuenta las inversiones crecientes en su promoción y formación ciudadana, al igual que la generación de nuevos elementos de desarrollo endógeno, de modo que se produzcan reorientaciones en las lógicas de avance social y oportunidades desde proyectos autónomos, autárquicos y solidarios entre diferentes colectivos en las localidades o municipios. 
Más aún, para lograr un proceso de desarrollo local endógeno con criterio colectivo y holístico (multidimensional-integral, participación-validación, comunión pública-privada), además del elemento expuesto por Palma (2006, p. 4) sobre la "necesaria presencia y participación de todos los actores, para contar con instancias de reflexión y crítica que puedan repensar lo local y orienten el proceso valiéndose de la negociación de los diferentes cuerpos intermedios interesados, fomentado así la cooperación y permitiendo la construcción de consensos que conlleven una visión común de desarrollo", es necesario en el escenario de los colectivos sociales (ciudades, pueblos, campos, comarcas, etc.) posibilitar e impulsar todos los "múltiples proyectos posibles", considerando las diferencias que producen las variadas formas de vida y aspiraciones que cada subconjunto comunitario dentro del gran complejo ciudadano poseen, y no se debe pensar en "una única apuesta" que cosifique y neutralice la diversidad de propósitos humanos, ni mucho menos que todos debamos agotar y encausar nuestra energía social en "un proyecto común" que en muchas ocasiones es el "proyecto de desarrollo de un sector y agentes particulares".

Finalmente, a partir de los elementos citados por Palma (2006, p. 5) para lograr el desarrollo local integral y luego de su explicación sobre las políticas de desarrollo social dentro del territorio comunal, creo que un proyecto solidario gestionado localmente con el concurso de toda la ciudadanía, debe tener como cimientos de su gran armazón estructural una sólida política educativa (formal e informal), de estímulo a la formación continua con la cual se promuevan las capacidades de generación de proyectos con base en iniciativas comunitarias.

\section{CONCLUSIONES}

A manera de colofón es pertinente aducir la necesidad de posicionar a la planificación territorial como un instrumento consustancial a la responsabilidad pública de un Estado de Derecho(s) por salvaguardar y amparar los principios fundantes de justicia social, equidad intergeneracional, sustentabilidad, etc.

Por consiguiente, su praxis e intervención se debe enfocar al fortalecimiento de la participación ciudadana, de modo que se propicie la construcción de una verdadera y legítima "democracia real" en la cual el planeamiento se asuma y entienda, en palabras de Francesco Indovina, "como un acto de gobierno colectivo asistido técnicamente" ${ }^{\prime 4}$, teniendo en cuenta que los profesionales de la planificación en vez de hacer las transformaciones, son los que deben coadyuvar y cooperar en su dirección para que esta sea conducida desde la óptica del interés general.

Incluso, desde esta perspectiva se podrá superar el papel asignado tradicionalmente al planificador como "arquitecto de la 
realidad" que indica las posibles dinámicas territoriales a desarrollar y define a partir de la zonificación dónde se debe construir o qué áreas son proclives a ser objeto de "renovación, esponjamiento, limpieza, reciclaje" o simplemente eliminación.

De forma similar, se proyecta como corolario y premisa básica de la gestión local, el empoderamiento comunitario, es decir, la necesidad de adelantar y promocionar el desarrollo social con la participación activa de todos los actores de la sociedad civil, conduciendo a una toma de decisiones integradora y cambiando el papel de las comunidades de receptoras de proyectos técnicos de desarrollo a promotores de sus propios destinos y posibilidades autónomas de futuros viables y deseados por ellos mismos.

En esta dirección es preciso considerar los principios introducidos por Andrés Palma (2006, p. 7), como son la perspectiva territorial, la descentralización y gobernabilidad, la equidad y accesibilidad, todas ellas hechas materia y realidad con objetivos como:

[...] orientar la gestión pública a las personas, trabajar con las familias en su propia comunidad, conectar las redes que conforman áreas de servicios y apoyos formales e informales a la familia y reconocer las experiencias institucionales y de la comunidad.

Ahora bien, reconociendo que en la actualidad se evidencian anhelos de cambio en la planificación de un enfoque estructural y de largo plazo hacia uno de carácter coyuntural, de corto plazo y de flexibilidad a la inversión especulativa propia del neoliberalismo, es imperativo imaginar, recrear y constituir diversos escenarios alternativos de hábitat popular planificado por las comunidades como respuesta social a la lógica y paradigma del "territorio como mercancía", para lo cual es menester la organización y cooperación ciudadana.

Asimismo, se requiere de una gestión comprometida y responsable por parte del Estado para superar la multiplicidad de conflictos creados por un sistema socio-político que ha privilegiado al capital financiero y no a las necesidades y urgencias vitales de la población que padece los efectos más dramáticos de la privatización y encarecimiento de los servicios sociales (salud, educación, transporte y movilidad, vivienda, alimentación, etc.). Es por ello que se reivindica y hace hincapié en la revaloración del sentido de un Estado verdaderamente democrático movilizado por el bienestar colectivo de la población y no como facilitador exclusivo de beneficios particulares, gremiales o de clase social.

Para terminar, en consonancia con el leitmotiv e inspiración de este escrito, como es "el proceso de enseñanza-aprendizaje fruto del ejercicio de escuchar y leer atentamente los argumentos de especialistas reconocidos por su trayectoria académica, profesional e intelectual, y a partir de allí, a través 
de la reflexión y discusión sobre sus ideas, construir una interpretación y lectura personal de la problemática objeto de análisis", se plantea entonces la explicación enunciada por Fernando de Terán (citado en Serra, 2009, p. 16) sobre el reto que representa la "complejidad del fenómeno urbano que vivimos en el que los límites de la ciudad se han diluido ocupando territorio de manera intensiva". En este sentido, y a manera de cierre sugestivo se exponen algunas de sus observaciones para que prosigamos la tarea de estudio y análisis de forma colectiva:

Lo que está claro es que el problema es general y nadie tiene la solución definitiva. La ciudad compacta que tanto gusta a los urbanistas europeos se ha visto superado por la realidad. Este modelo ha hecho crisis. Lo que se ha expandido es la ciudad dispersa, el modelo americano de ciudad difusa que se ha ido imponiendo por la influencia mediática y porque la gente, en realidad, prefiere vivir en estos chalets o adosados de la periferia. Sólo los intelectuales y los ecologistas conscientes del despilfarro de energía y territorio que esto supone defienden la ciudad compacta. $Y$ tienen razón. Yo también pienso que es mejor, pero conseguirla no es ya un problema del urbanismo sino de la pedagogía.

Pasa lo mismo, dice De Terán, con el tema de la sostenibilidad. La legislación española y la de las 17 autonomías incluye estos temas en su gran mayoría, no hace falta una revolución metodológica, pero es un problema de sensibilidad, de darle más importancia a este tema y también de nuevo, de voluntad política. El problema es que gran parte de la expansión urbanística desordenada que tantas críticas ha generado incluso de la Unión Europea se ha hecho dentro de la más estricta legalidad. Ahora parece que se ha parado por la crisis, pero no porque haya una reflexión sobre lo que se ha hecho mal, que es lo que tocaría. Están esperando a ver cuándo vuelve a haber liquidez para continuar igual. Es entre los jóvenes ecologistas, en las facultades de geografía o en algunas de ingeniería en donde se preocupan por este tema. En las escuelas de arquitectura siguen todos encandilados con el proyecto bonito y ni siquiera se enseña bien cómo hacer un plan...

Pero lo que toca ahora no es tanto pensar en nuevos planes de desarrollo sino en cómo se puede compactar y estructurar la ciudad difusa que ya se ha construido para minimizar los daños. Es uno de los grandes retos del futuro inmediato, sin duda. Lo que está claro es que 
tendríamos que evitar seguir proyectando ciudad difusa nueva. Pero claro, si nos salen los políticos con sus mayorías absolutas, ¿qué vamos a hacer? (Serra, 2009, p. 17).

\section{BIBLIOGRAFÍA}

- Aprile-Gniset, J. (2007). Memorias del destierro y del exilio. En: Cátedra Jorge Eliécer Gaitán: Tierras y conflicto. Cali-Bogotá: Universidad Nacional de Colombia.

- Barón, J.D. (2002). Las regiones económicas de Colombia: Un análisis de clusters. Documentos de trabajo sobre economía regional, No. 23. Centro de Estudios Económicos Regionales. Cartagena de Indias: Banco de la República.

- Borja, J. (2003). La ciudad conquistada. Madrid: Alianza Editorial.

- (2004a). Los derechos ciudadanos. Estudios, No. 51. Madrid: Fundación Alternativas.

- $\quad$ (2004b). La ciudad futura como proyecto colectivo. Los Monográficos de BMM Número 4. FORUM Barcelona.

- _ (2005). Un futur urbà amb un cor antic. Catálogo de la exposición Quórum. Comisaría: Rosa Pera, ICUB.

- (2007). Espai públic i memoria democràtica. Ponencia presentada en el Coloquio Internacional sobre Políticas Públicas de la Memoria, organizada por el Memorial Democràtic-Generalitat de Catalunya (octubre de 2007). Publicado en la revista Mirades, No. 1 (2008), por el Grupo ICV-EUiA-EPM de la Diputación de Barcelona.

- (2009). La ciudad, entre la desposesión y la reconquista. Barcelona Metrópolis, Revista de Información y Pensamiento Urbanos. Disponible en: http://www.barcelonametropolis.cat/es/page.asp?id $=21 \& u i=229$

- (2010a). Siete puntos para el debate ciudadano. Obtenido el 5 de abril de 2010 de http://informacionestrategica.wordpress.com/2010/0 4/05/jordi-borja-siete-puntos-para-el-debateciudadano

- (2010b). Luces y Sombras del Urbanismo de Barcelona. Colección Gestión de la Ciudad, 2. Barcelona: Editorial UOC.

- . (2011). El hipotético modelo Barcelona y su relación con otras ciudades. Consideraciones sobre el modelo y comparación con los casos de Bilbao, Monterrey, Rio de Janeiro y Buenos Aires. Carajillo de la ciudad, Revista Digital del Programa de Gestión de la Ciudad, Año 3. Universidad Oberta de Catalunya, UOC. Disponible 
http://www.cafedelasciudades.com.ar/carajillo/10_ar t3.htm

(2012). Lectura de Tesis Doctoral: Revolución urbana y derechos ciudadanos. Universidad de Barcelona. Video editado por: Universitat Oberta de Catalunya. Obtenido el 31 de mayo de 2012 de http://www.youtube.com/watch?v=0YJZEaaKRZM

- Borja, J. \& Muxí, Z. (2001). L'espai públic: Ciutat y ciutadania. Barcelona: Diputació de Barcelona.

(2002). Centros y espacios públicos como oportunidades. Perfiles Latinoamericanos, 19, 115-130.

- Cámara de Comercio de Bogotá -CCB-. (s.f.). Ciudad región-global. Aportes de Experiencias internacionales para Bogotá y Cundinamarca. Capítulo II. Planificación y diseño urbano y regional en Curitiba: El último medio siglo. Disponible en: http://camara.ccb.org.co/documentos/4412_parte_2. pdf

- Capel, H. (2005). El modelo Barcelona: Un examen crítico. Barcelona: Ediciones del Serbal.

- _ (2006). De nuevo el modelo Barcelona y el debate sobre el urbanismo Barcelonés. Biblio $3 W$, XI(629). Barcelona: Universidad de Barcelona. Obtenido el 25 de enero de 2006 de http://www.ub.edu/geocrit/b3w-629.htm (2007). El debate sobre la construcción de la

- ciudad y el llamado "modelo Barcelona". Scripta Nova, XI(233). Barcelona: Universidad de Barcelona. Obtenido el 15 de febrero de 2007 de http://www.ub.edu/geocrit/sn/sn-233.htm

- Casellas, A. (2006). Las limitaciones del "modelo Barcelona". Una lectura desde el Urban Regime Analysis. Documents d'anàlisi Geogràfica, 48, 61-81. Ed. Universitat Autònoma de Barcelona - Universitat de Girona.

- Ciccolella, P. (2004). Metrópolis en transición: Buenos Aires al desnudo entre la expansión económica y la crisis. En Aguilar A. (coord.). Procesos metropolitanos y grandes ciudades. Dinámicas recientes en México y otros países (pp. 53- 77). México: Honorable Cámara de la LIX Legislatura, Universidad Nacional Autónoma de México - Instituto de Geografía, Centro Regional de Investigaciones Multidisciplinarias, y Consejo Nacional de Ciencia y Tecnología.

- Corti, M. (2008). Curitiba, "do modelo a modelagem". La construcción y los usos de una imagen urbana. Revista digital Café de las ciudades, Año 7, No. 67. Disponible en:

http://www.cafedelasciudades.com.ar/urbanidad_67. htm

- Delgado, M. (2004). Ciudades de mentira. El turismo cultural como estrategia de desactivación urbana. Tourismes. La derrota de la dissensió. Itineraris crítics. Barcelona: Fundació Antoni Tàpies. p. 367-372. 

Barcelona" a la Barcelona real. Barcelona: Edicions de 1984.

- . (2007). La ciudad mentirosa. Fraude y miseria del "modelo Barcelona". Madrid: Los libros de la Catarata.

- De Mattos, C. (2004). Santiago de Chile de cara a la globalización ¿otra ciudad? En: Aguilar A. (coord.). Procesos metropolitanos y grandes ciudades. Dinámicas recientes en México y otros países (pp. 1952). México: Honorable Cámara de la LIX Legislatura, Universidad Nacional Autónoma de México - Instituto de Geografía, Centro Regional de Investigaciones Multidisciplinarias, y Consejo Nacional de Ciencia y Tecnología.

- Doxiadis, K.A. \& Papaioannou, J.G. (1974). Ecumenopolis: The Inevitable City of the Future. Athens: Athens Center of Ekistics.

- Generalitat de Catalunya (1995). Pla Territorial General de Catalunya. Llei 1/1995. Disponible en: www.gencat.cat

- Gottmann, J. (1961). Megalopolis. The urbanized northeastern seaboard of the United States. Cambridge, Massachusetts: MIT Press.

- Guidini, R. (2009). Aprendiendo una lección de Curitiba. Efectos perversos de una política orientada al transporte público y al medio ambiente. Ciudades para un futuro más sostenible, Boletín CF+S, 42/43. Simposio Internacional Desarrollo, Ciudad y Sostenibilidad. La Serena, Chile: Ed. Universidad Politécnica de Madrid, Escuela Técnica Superior de Arquitectura de Madrid. Disponible en: http://habitat.aq.upm.es/boletin/n42/ab-rghi.html

- Gwynne, R.N. (1985). Industrialization and urbanization in Latin America. London: Croom Helm.

- Harvey, D. (2007). Breve historia del neoliberalismo. Madrid: Ediciones Akal.

- Harvey, D. \& Smith, N. (2005). Capital financiero, propiedad inmobiliaria y cultura. Barcelona; Bellaterra (Cedanyola del Vallès): Museu d'Art Contemporani de Barcelona; Servei de Publicacions de la Universitat Autònoma de Barcelona.

- Indovina, F. (2004). Per què el planejament avui? Diputació de Barcelona, Xarxa de municipis. Territori i ciutat. Butlletí digital de I'Oficina Tècnica de Cooperació, No. 17.

- Instituto Geográfico Agustín Codazzi -IGAC-. (1990). Estructura urbano regional en Colombia. Serie Análisis Geográfico, No. 17. Bogotá: IGAC.

- Janoschka, M. (2000). Reich und arm in Buenos Aires. Barrios privados als neue Form der Suburbanisierung. Praxis Geographie, 30(12), 60-62.

- . (2002a). El nuevo modelo de la ciudad latinoamericana: fragmentación y privatización. EURE, Santiago de Chile: Estudios urbano regionales, 28(85), 11.30. 

(2002b). Wohlstand hinter Mauern. Private Urbanisierungen in Buenos Aires. Wien: Forschungsberichte des Institus für Stadt- und Regionalforschung 28, Österreichische Akademie der Wissenschaften. En prensa. (2003). Nordelta - ciudad cerrada. El análisis de un nuevo estilo de vida en el gran Buenos Aires. V Coloquio Internacional de Geocrítica, La vivienda urbana y la construcción del espacio social en la ciudad. Barcelona, 27-30 de Mayo, 2003.

- Janoschka, M. \& Borsdorf, A. (2005). Condominios fechados and barrios privados. The rise of private residential neighbourhoods in Latin America. In: G. Glasze, C. Webster and K. Frantz (eds.). Private Cities. Global and Local Perspectives (pp. 92-108). London \& New York: Routledge.

- Márquez, C.G. (2004). Mapas de un fracaso: Naturaleza y conflicto en Colombia. Bogotá: Ed. Universidad Nacional de Colombia, Instituto de Estudios Ambientales (IDEA).

- Maskrey, A. (comp.). (1993) Los desastres no son naturales. LA RED, Red de Estudios Sociales en Prevención de Desastres en América Latina.

- McKenzie, E. (1994). Privatopia. Homeowner Associations and the Rise of Residential Private Government. New Haven: Yale University Press.

- Monclús, F.J. (2003). El 'modelo Barcelona' ¿Una fórmula original? De la 'reconstrucción' a los proyectos urbanos estratégicos (1997-2004). Perspectivas Urbanas / Urban Perspectives, 18(4), 399-421. Disponible https://upcommons.upc.edu/revistes/bitstream/2099 1703/2/art03-3.pdf

- Montaner, J.M. \& Muxí, Z. (2006). Curitiba: Hacia la ciudad ecológica. La Vanguardia. Obtenido el 16 de julio de 2006 de http://arquifuturo.jimdo.com/curitiba-ciudadejempla

- Montoya, J.W. (2006). Cambio urbano y evolución discursiva en el análisis de la ciudad Latinoamericana: De la dependencia a la globalización. Bogotá: Universidad Nacional de Colombia, Facultad de Ciencias Humanas, Departamento de Geografía. Serie Trabajos en Geografía.

- Muñoz, F. (2008). Urbanalización: paisajes comunes, lugares globales. Barcelona: Ed. Gustavo Gili.

- Nel.lo i Colom, O. (2010). El planeamiento territorial en Cataluña. Cuadernos Geográficos, 47, 131-167.

- Oliveira, O. \& Roberts, B. (1996). Urban development and social inequality in Latin-American. In: J. Gugler (ed.). The urban transformation of developing world. New York: Oxford University Press.

- Palma, A. (2006). Desarrollo Social y la Gestión Local. Revista Electrónica Agenda Pública, Año V, No. 10.

- Prévôt-Schapira, M.F. (2000). Segregación, fragmentación, secesión. Hacia una nueva geografía 
social en la aglomeración de Buenos Aires. Economía, Sociedad y Territorio, 2(7), 405-431.

- - (2002). Buenos Aires en los años 90: metropolización y desigualdades. EURE Santiago de Chile, Instituto de Estudios Urbanos, 28(85), 31-50.

- Romero, H.; Fuentes, C. y Smith, P. (2010). Ecología política de los riesgos naturales y de la contaminación ambiental en Santiago de Chile: Necesidad de Justicia ambiental. Scripta Nova, XIV, No. 331 (52). Barcelona: Universidad de Barcelona. Obtenido el 1 de agosto de 2010 de http://www.ub.edu/geocrit/sn/sn-331/sn-33152.htm

- Salazar, P. (2011). Plan Nacional de Desarrollo 20102014 "Prosperidad para todos". Revista Espacio Crítico, 14, 3-42. Bogotá.

- Sánchez, F. y Moura, R. (2005). Ciudades modelo: estrategias convergentes para su difusión internacional. EURE Santiago de Chile, Estudios urbano regionales, 31(93), 21-34.

- Sarmiento, A.L. (2011). Plan Nacional de Desarrollo: Prosperidad para todos. Le Monde Diplomatique, 97. Bogotá: Edición Colombia.

- Sauri, P.D. (2003). Tendencias recientes en el análisis geográfico de los riesgos ambientales. ÁREAS, Revista de Ciencias Sociales, 23, 17-30. Murcia: Edit.um. Ediciones de la Universidad de Murcia.

- Serra, C. (2009). La gran excusa Cerdá. El País, Babelia, septiembre 26.

- Svampa, M. (2001). Los que ganaron. La vida en los countries y barrios privados. Buenos Aires: Biblos.

- Torres, H. (2000). Procesos recientes de fragmentación socioespacial en Buenos Aires: la suburbanización de las élites. Mundo Urbano, 3. Disponible en: www.argiropolis.com.ar/mundourbano/anteriores/Tr es/Torres.htm

- (2001). Cambios socioterritoriales en Buenos Aires durante la década de 1990. EURE Santiago de Chile, Instituto de Estudios Urbanos, 27(80), 33-56.

- Vidal-Koppmann, S. (2001). Segregación residencial y apropiación del espacio: la migración hacia las urbanizaciones cerradas del Área metropolitana de Buenos Aires (Argentina). Scripta Nova, Revista Electrónica de Geografía y Ciencias Sociales, 94. Obtenido el 2 de mayo de 2002 de www.ub.es/geocrit/sn-94-70.htm (2002). Nuevas fronteras intraurbanas: de los barrios privados a los pueblos privados. Buenos Aires, Argentina. En: Cabrales B. L. (coord.). Latinoamérica: Países abiertos, ciudades cerradas (pp. 261-286). México: Universidad de Guadalajara, Centro Universitario de Ciencias Sociales y Humanidades, y UNESCO.

- . (2010). Las ciudades valladas y su relación con el entorno. Una aproximación a las transformaciones socio-territoriales de la expansión metropolitana de Buenos Aires. En: Vidal K. S., Perahia 
R. (comps.). Cuestiones territoriales en la región metropolitana de Buenos Aires (pp. 57-67). Buenos Aires: Editorial FADU-Nobuko.

- . (2012). Los nuevos territorios urbanos del siglo XXI y su inserción político-administrativa metropolitana. El caso de las ciudades privadas en la región metropolitana de Buenos Aires. Universidad de Buenos Aires. En: Memorias del XII Coloquio Internacional de Geocrítica. Independencias $y$ construcción de Estados Nacionales: Poder, territorialización y socialización, siglos XIX-XX. Mesa temática 7B: Transformaciones urbanas y periurbanas. Bogotá, 7-11 de mayo de 2012. Disponible en: http://www.ub.edu/geocrit/coloquio2012/actas/07-SVidal.pdf

1. Administrador Ambiental, Universidad Tecnológica de Pereira (UTP). Magíster en Geografía, Universidad Pedagógica y Tecnológica de Colombia (UPTC) Instituto Geográfico Agustín Codazzi (IGAC). Magíster en Planificación Territorial y Gestión Ambiental, Universidad de Barcelona (UB). Docente Departamento de Historia y Geografía, Universidad de Caldas, Colombia. jorgeandres.rivera@ucaldas.edu.co proyecto académico: http://www.riverapabon.blogspot.com, http://www.geonotassonarterrestrecafetero.blogspot.com

2. Este artículo se soporta en los argumentos y elementos analíticos que sobresalieron en el desarrollo de diferentes exposiciones, conferencias, seminarios, foros y coloquios internacionales que han versado sobre la planificación territorial y la gestión urbana (citados en la bibliografía cuando se ha hecho alguna reseña o memoria del evento) a los cuales he asistido durante mi período de formación de posgrado en la Universidad de Barcelona entre los años 2008-2012.

3. Para ejemplificar las pugnas políticas que se tejen alrededor de los diferentes paradigmas en discusión (o a veces semejantes), se exponen las siguientes editoriales y notas de opinión sobre el caso de Bogotá y su plan de desarrollo, el debate de su financiación y los modelos de ciudad en juego: ciudad compacta vs. el crecimiento en expansión rururbana, metropolitana y regional:

http://www.elespectador.com/opinion/editorial/artic ulo-343335-discutir-esta-juego; http://www.eltiempo.com/opinion/editoriales/ ARTICULO-WEB-NEW_NOTA_INTERIOR11900923.html; http://www.elespectador.com/noticias/bogota/ articulo-325765-expansion-de-bogota-si-tienefuturo-lonja;

http://www.arcoiris.com.co/2012/06/plan-dedesarrollo-balance-agridulcel; 
http://www.elespectador.com/noticias/bogota/articul o-348292-el-plan-una-quimera;

http://www.eltiempo.com/colombia/bogota/

ARTICULO-WEB-NEW_NOTA_INTERIOR11856603.html;

http://www.elespectador.com/impresol

bogota/articulo-345900-secretaria-de-planeacion-

intenta-convencer-al-concejo-de-aprobar;

http://www.uniandes.edu.co/component/content/arti

clel

683-ies-viable-el-plan-de-desarrollo-de-bogota

4. El any Cerdà, se celebró desde junio de 2009 a junio de 2010 con motivo del 150 o aniversario de la aprobación del Plan de Reforma y Ensanche de Barcelona (7 de Junio de 1859). www.anycerda.org (citado en Serra, Catalina. La gran excusa Cerdà. El País, Babelia, p. 17. Fecha de Publicación: 26-09-09).

5. El autor afirma que "la mayoría estamos de acuerdo en que hay que limitar esta ciudad difusa que se expande sin control consumiendo gran cantidad de recursos, pero lo que piden los políticos son planes que les permitan hacer este tipo de ciudad, y eso es lo que se hace. Lo he comprobado, la mayor parte de los planes en el litoral valenciano son de este tipo, de ciudad difusa y dispersa. Están aprobados, son legales y nadie ha protestado. Es más, ganan elecciones con mayorías absolutas. Están respaldados política y socialmente" (citado en Serra, 2009, p. 16).

6. Con relación a las polémicas del papel y responsabilidad de los técnicos en los problemas urbanos y sus soluciones, véase el caso de Bogotá: http://n.eltiempo.com/opinion/columnistas/enriques antosmolanol

de-urbanismo-de-honradez-de-tecnica/10944612;

http://www.cambio.com.co/paiscambiol 864/ARTICULO-WEB-NOTA INTERIOR CAMBIO7055310.html:

http://www.rcnradio.com/node/69820

7. Como muestra, hago referencia de algunas noticias sobre la postura del gobierno colombiano, en cabeza del Presidente Juan Manuel Santos, ante la situación de emergencia generalizada que vivió el país durante los años 2010 y 2011, a raíz de la "ola invernal" o período de lluvias intensas, en la cual se enfocó y concentró la responsabilidad técnica-política en las autoridades ambientales del orden departamental y macro-regional, como son las Corporaciones Autónomas Regionales (CAR's): http:/lwww.eluniversal.com.co/cartagena/nacionall presidente-santos-regañó-las-car; http://m.eltiempo.com/political las-car-deben-ser-reformadas-afirma-el-presidentesantos/8792647;

http://www.caracol.com.co/noticias/actualidad/ presidente-santos-recorta-recursos-a-las-carpor-ineficiencia-para-afrontar-crisisinvernal/20101214/nota/1398543.aspx; 
http://www.elespectador.co/noticias/politica/ articulo-246587-car-seran-mas-gobernables-santos Sobre la reforma a las CAR y la institucionalidad ambiental como consecuencia de la "crisis invernal", véase:

http://wsp.presidencia.gov.co/Prensa/2011/Enero/Pa ginas/20110119_02.aspx;

http://reexistencia.wordpress.com/2011/01/28/ el-asalto-neoliberal-de-santos-a-las-corporacionesautonomas-regionales-carl; http://www.lasillavacia.com/historia/lasindignaciones-de-santos-34312

8. Para una lectura desde las ciencias sociales y la ecología política sobre la producción de eventos catastróficos y de la generación de desastres, véase: http://www.desenredando.org/public/libros/1993/ldn $\mathrm{snl}$ LosDesastresNoSonNaturales-1.0.0.pdf; http://www.ub.edu/geocrit/sn/sn-331/sn-331-52.htm; http://revistas.um.es/areas/article/view/117861; http://www.ecologiapolitica.info/ep/36/36.htm; etc.

9. Información general sobre el Plan Territorial General de Cataluña: página web de la Generalitat de Catalunya: www.gencat.cat; y específicamente: http://www20.gencat.cat/portal/site/territori/ menuitem.2a0ef7c1d39370645f13ae92b0c0e1a0/?vg nextoid=3440a9c1aa9b7210 VgnVCM1000008d0c1e0 aRCRD

Para algunos trabajos de contextualización y reflexión sobre la planificación territorial en Cataluña: http://www.ugr.es/ cuadgeo/docs/articulos/047/047006.pdf;

http://www.apgeo.pt/files/docs/CD_X_Coloquio_lber ico_Geografia/pdfs/106.pdf

10. Para información de este megaproyecto: http://blogs.publico.es/dominiopublicol

5419/eurovegas-paradigma-del-modelo-neoliberal/; http://politica.elpais.com/politica/2012/06/27/ actualidad/1340813956_520873.html
Debates
sobre
Eurovegas:

http://www.youtube.com/watch?v=H2vDNjWLH8Q\&f eature=related;

http://www.youtube.com/watch?v=Uekh6KquCvE\&f eature=related;

http://www.youtube.com/watch?v=8196ixuNSaw\&fe ature=related

11. http://www.rtve.es/noticias/20120625/ubicacion -eurovegas-entre-barcelona-madrid-se-decidiraprincipios-septiembre/539663.shtml

12. Presentación de artículos, columnas y exposiciones del autor en: http:/ljoaquimnadal.cat/

13. Conferencia inaugural del Máster Oficial Europeo en Planificación Territorial y Gestión Ambiental, cohorte 2011-2013, celebrada en la Facultad de Geografía e Historia, el día 14 de octubre de 2011. 
14. Versión digital - síntesis del texto: http://rsalas.webs.ull.es/rsalas/materiales/at\%20Muñ oz,\%20F.\%20Urbanalización.pdf

15. En este caso, los dos autores ejemplifican este cambio de orientación con el análisis que debe hacerse de la difusión urbana, reconociendo la certera interpretación que vienen haciendo los geógrafos de este proceso (que los diferencia de otros profesionales), no solo desde su enfoque de estudio multiescalar de un problema de envergadura supralocal, sino también a la luz de las dinámicas poblacionales, la desestructuración de espacialidades sociales históricas y la creación de nuevas centralidades que tienen su lógica en razones diferentes a los de la etapa industrial, etc.

16. http://www.kreanta.org/cv/jordi_borja_sebastia.html; http:/ljordiborja.blogspot.com.es/

17. Participación con/en movimientos vecinales y explicaciones sobre el urbanismo social y la ciudad democrática:

http://www.youtube.com/watch?v=vgkRrOJto1A\&fe ature=player_embedded\#; http://www.youtube.com/watch?v=p-xVkjuLdr8

18. Lectura de tesis doctoral de Jordi Borja en la Universidad de Barcelona, presentado el 31-05-2012. Video editado por la Universitat Oberta de Catalunya: http://www.youtube.com/watch?v=0YJZEaaKRZM

19. Citado con base en la invitación realizada por el autor para asistir a la lectura de la tesis doctoral, la cual fue publicada en el espacio web de Geocrítica en facebook: http://www.facebook.com/pages/Geocr\%C3\%ADtica /130695177028543?filter=4

20. Algunas obras de referencia sobre esta temática son: Borja y Muxí (2001, 2002), Borja (2003, 2004a, 2004b, 2005, 2007, 2010a).

21. Véase Bitácora Barcelona (citado en http://wwww.riverapabon.blogspot.com).

22. En este sentido han ejercido una gran influencia la exhumación de una historia y una tradición distintivamente catalanas y la difusión comercial de sus sólidos logros artísticos y de su legado arquitectónico (Gaudí, por supuesto), junto con sus marcas distintivas en cuanto a estilos de vida y tradiciones literarias, con el respaldo de un aluvión de libros, exposiciones y eventos culturales que celebran su carácter distintivo (Harvey \& Smith, 2005, p. 48-49).

23. Entre los hitos y nuevos adornos arquitectónicos de "marca" de la ciudad global en Barcelona se destacan, por ejemplo, la torre de telecomunicaciones de Norman Foster, el flamante y blanco Museu d'Art Contemporani de Barcelona (MACBA) de Richard Meier, situado en medio del tejido urbano, un tanto degradado, del casco antiguo; el edificio central del Forum de las Culturas (2004) de Jacques Herzog y Pierre de Mouron; la Torre Agbar (Aguas de Barcelona) de Jean Nouvel, entre otros (Harvey \& Smith, 2005, p. 49).

24. Bibliotecas en las diferentes escalas -barrial, comunal, municipal, metropolitana-; guarderías y jardines 
infantiles, colegios, centros de formación artística y profesional; centros de salud y hospitales; áreas deportivas, etc.

25. Parques abiertos y gratuitos; alamedas, rondas de ríos y corredores ambientales, senderos para la interpretación y lúdica ambiental.

26. Perfil profesional de Ferran Miralles: http://wwww.seguretat.org/ides/ca/llistat-autor/fitxaautor.html?id=69

27. Proyectos y Planes Territoriales coordinados por Joan Fortuny:

http://www.gencat.cat/odecat/html/descargar/Fortun y.PDF;

http://www20.gencat.cat/docs/ptop/Home/

Serveis\%20i\%20tramits/Biblioteca\%20i\%20docume ntacio/Planificacio\%20territorial/Publicacions/Planej ament\%20territorial/Pla\%20territorial\%

20de\%20les\%20Comarques\%20Gironines/cap0_Pla territorial_Girona.pdf

28. Trabajos desarrollados e investidura doctor "honoris causa" de Juli Esteban: http://www.upc.edu/saladepremsa/al-dia/mesnoticies/ el-arquitecto-y-urbanista-juli-esteban-serainvestidodoctor-2018honoris-causa2019-por-la-upc-1

29. Véase ejemplos de periurbanización en diferentes ciudades latinoamericanas, en: http://www.historiaygeografiaucaldas.blogspot.com. esl

30. http://www.evanmckenzie.com/

31. Para presentar el panorama de las ideas aplicado en un caso concreto como es el de Chile, expreso con "agrado geográfico" y complacencia la audaz y acertada decisión que tomara en su momento el gobierno chileno liderado por Michelle Bachelet, al "territorializar las políticas de desarrollo social", dando un paso hacia adelante en la perspectiva de superar los bajos resultados obtenidos en este tipo de políticas en América Latina debido a la ejecución permanente de modelos abstractos que "nunca aterrizan" o miran las realidades locales, pecando por tener siempre, como lo enuncia Andrés Palma (2006, p. 5) "diseños estandarizados, homogéneos para todas las regiones y comunas del país". Este proyecto político sintetizado en el Sistema de Protección Social "Chile Solidario", auguraba un trabajo positivo (aunque no por ello desprovisto de conflictividades en su aplicación), al plantear como eje central y principio tutelar el desarrollo de estrategias y acciones diferenciadas en función de los geoespacios de problemas sociales que tiene el país austral, y no en grandes ideas de papel.

32. En este contexto de prevalencia del discurso y acción "modernizadora", lo que se empezó a configurar fue la concentración por parte de las élites regionales de los proyectos productivos, tanto en el ámbito urbano con la industrialización, como en el mundo rural con la 
implementación de la "revolución verde" o modelo de desarrollo agro-industrial, que ha tenido como requisito axiomático e inequívoco la concentración de la tierra para poder obtener mayor productividad y rendimientos económicos a partir del establecimiento de monocultivos (caña de azúcar, café, plátano, entre otros productos agrícolas, y en la actualidad, palma para "biocombustibles").

33. Durante los años 1950-1960, se creó la CVC y los programas de desarrollo departamental para Atlántico, Boyacá, Santander, Norte de Santander, Caldas, el plan para la costa Atlántica, entre otros. No obstante, la deficiencia en los recursos económicos y la forma de administración no permitió la ejecución de estos planes. Sin lugar a dudas, esto fue consecuencia del mantenimiento de un régimen centralista, en el cual las instituciones de planificación territorial regional no contaron con sistemas financieros y operativos adecuados para adelantar dichos procesos.

34. Plan decenal de desarrollo (1960-1970); las cuatro estrategias (1970-1974); para cerrar la brecha (19741978); plan de integración nacional (1978-1982); cambio con equidad (1982-1986); plan de economía social (1986-1990); la revolución pacífica (1990-1994); el salto social (1994-1998); cambio para construir la paz (1998-2002); hacia un estado comunitario (2002-2006); Estado comunitario: desarrollo para todos (2006-2010); prosperidad para todos (2010-2014).

35. En efecto, se puede afirmar que el carácter permanente de la primacía urbana se debe a la existencia de economías nacionales estructuradas en función de los intereses de los centros de poder del sistema económico global (históricamente determinadas en el capitalismo dependiente) y no en función de una economía interna sólida que responda a un proyecto endógeno de inclusión ciudadana y consenso nacional. Es por ello, que contrario a lo expuesto por los teóricos de la modernización y el librecambio, al afirmar que la industrialización y la liberalización económica estimulan la desconcentración espacial de las actividades económicas, y que al largo plazo, resuelven la desigualdad espacial en el desarrollo, lo que se ha afianzado es el reforzamiento de la primacía.

36. Durante la década de los setenta se inicia un nuevo ciclo de crisis y recesión económica que marca el fin de un período económico de expansión que había empezado en 1930, el cual se apoyaba fundamentalmente en la reducción de la dependencia tanto en el consumo de manufacturas importadas como de la exportación de materias primas. De este modo, se presenta un panorama poco optimista sobre la posibilidad de darle continuidad al proyecto de modernización industrial, toda vez que se advierte una carencia de recursos y una inminente desfinanciación para el desarrollo de esta política. Ante esta situación, los Estados se ven forzados a liberalizar sus 
economías, y así satisfacer las exigencias de los prestamistas del sector finaciero internacional.

37. Frente a esta crisis económica, el gobierno colombiano y en general los Estados latinoamericanos tomaron la decisión, con cierto nivel de presión por parte de las agencias internacionales, de superarla a través de endeudamiento, que ya no era proporcionado por los bancos centrales de los Estados desarrollados, sino por la banca internacional. Como testimonio, se observó la contracción de la participación del sector público de Estados Unidos y de otros países en la provisión de recursos de endeudamiento. Montoya (2006, p. 19) ejemplifica esta situación con base en las siguientes cifras, enunciadas por Gwynne (1985, p. 10): "Ios flujos financieros netos pasaron de 2,6 millardos en 1966 a 21,8 en 1978, a la vez que los bancos subían su participación de un 10\% en 1966 a un 57\% en 1978".

38. La reducción de flujos de capital para las inversiones de carácter nacional, por la dificultad o incapacidad de pago de los prestamos y endeudamientos adquiridos de manera exagerada en la década anterior, aunados al crecimiento de la inflación, llevaron a los diferentes países del continente a una fase de recesión, denominada como "la década perdida", en la cual se frenaron los sectores que poseían mayor dinamismo resultado de la ejecución de las políticas estatales de desarrollo económico vía industrialización.

39. Los Consejos Regionales de Planificación del Desarrollo Económico y Social (CORPES) fueron: Occidente, Centro Oriente, Costa Atlántica, Orinoquia y Amazonia. El instrumento de desarrollo era la descentralización, con la cual se podía proveer a estas entidades de mayor capacidad y autonomía (tanto administrativa como en las rentas básicas) para generar coordinación interinstitucional entre los diferentes niveles administrativos del país.

40. Chang, H.-J. (2003). Globalization, economic development and the role of the state. London: Zed Books; Jessop, B. (2002).Liberalism, neoliberalism and urban governance. A state-theoretical perspective. Antipode XXXIV, 3, 452-472 (citado en Harvey, 2007, p. 73).

41. Para una ampliación de los proyectos productivos que se podrían desarrollar en Colombia sobre la base de iniciativas endógenas y soberanas a partir de las tradiciones laborales, artes y oficios, véase el lúcido artículo del escritor y poeta William Ospina, disponible en: http://www.elespectador.com/opinion/columna365231-memoria-y-futuro [4 de agosto de 2012].

42. En cuanto al aprovechamiento de los recursos mineros, se puede observar en el mapa sobre cartografía de la desposesión nacional que los proyectos de interés nacional (UPME) coinciden, en gran medida, con áreas de resguardos indígenas (o en espacios de influencia directa), como son por ejemplo, la zona pacíficaoccidental, norte y oriente del país. Asimismo, esto demuestra que, a pesar de la intención del Plan 
Nacional de Desarrollo de promover e impulsar la economía en la periferia con este tipo de explotaciones, la minería entra en contradicción con la autonomía de los territorios indígenas, y además, en contra de su voluntad, ya que revive esta actividad productiva causante de la disminución de la población nativa durante todo el período colonial.

43. Sobre los problemas y conflictos ambientales producidos en el marco de la lucha por el control social, territorial y productivo en Colombia, véase: Márquez (2004). Algunos mapas disponibles en: http://www.sogeocol.edu.co/documentos/07bmap.p df

De igual modo, para una explicación de los impactos ambientales generados por el "modelo de desarrollo" extractivo minero y de biocombustibles desde una perspectiva de la ecología política y la economía ecológica, véase la entrevista realizada a Joan Martínez Alier:

http://www.youtube.com/watch?v=n14sBs_Rmal Finalmente, se presentan los pronunciamientos de las organizaciones sociales y populares sobre los efectos negativos de las políticas y estrategias de desarrollo estatal, en especial, de la "locomotora minera": http://notiagen.wordpress.com/2012/08/02/

defender-la-vida-y-el-territorio-mensaje-de-lamarcha

-para-frenar-la-politica-minera-del-gobiernol; http://www.colectivodeabogados.org/Notiagen

44. http://geographiando.hrev.org/mapas/

45. Este tipo de dinámicas sociales son el resultado de un proceso constante de la Coalición de Movimientos Sociales de Colombia representados en el Congreso Nacional de Tierras, Territorios y Soberanías: http://notiagen.wordpress.com/2011/10/02/ movilizacion-y-ordenamiento-territorial-propio-sediscute-en-el-congreso-de-tierras/

46. Debates sobre tierras y territorios: https://notiagen.wordpress.com/2011/10/03/ejetierras-y-territorios-videol

47. El autor también fue Director del Programa de Gerencia Social y Políticas Públicas de FLACSO, labor que adelantó durante los años 2005-2010.

48. Como ejemplo están los casos del "Modelo Barcelona y Curitiba" que se reproducen por lo largo y ancho de América Latina. Del modelo Barcelona y los debates en torno a él, véase: Borja $(2009,2010 b, 2011)$, Capel (2005, 2006, 2007), Casellas (2006), Delgado (2004, 2005, 2007), Monclús (2003). En cuanto a las diferentes posturas frente al "modelo Curitiba", véase: Corti (2008), Montaner y Muxí (2006), Guidini (2009), Sánchez y Moura (2005). Con base en los planteamientos señalados por los autores precedentes, véase la propuesta de estandarización "modélica" para el desarrollo urbano que tiene como trasfondo la promoción del ideario de la ciudad como mercancía y medio de atracción de ciudadanos, consumidores e 
inversionistas: Cámara de Comercio de Bogotá -CCB(s.f.).

49. Idea enunciada por Francesco Indovina (2004) en la presentación del libro "Planeamiento urbanístico: de la controversia a la renovación", editado por la Diputación de Barcelona, Número 2 de la colección Territorio y Gobierno. 